\title{
The Effects of Explicit versus Parameterized Convection on the MJO in a Large-Domain High-Resolution Tropical Case Study. Part I: Characterization of Large-Scale Organization and Propagation*
}

\author{
Christopher E. Holloway and Steven J. WoOlnough \\ NCAS-Climate, Department of Meteorology, University of Reading, Reading, United Kingdom \\ GRENVILLE M. S. LISTER \\ NCAS-CMS, Department of Meteorology, University of Reading, Reading, United Kingdom
}

(Manuscript received 13 August 2012, in final form 2 November 2012)

\begin{abstract}
High-resolution simulations over a large tropical domain $\left(\sim 20^{\circ} \mathrm{S}-20^{\circ} \mathrm{N}, 42^{\circ} \mathrm{E}-180^{\circ}\right)$ using both explicit and parameterized convection are analyzed and compared to observations during a 10-day case study of an active Madden-Julian oscillation (MJO) event. The parameterized convection model simulations at both 40- and $12-\mathrm{km}$ grid spacing have a very weak MJO signal and little eastward propagation. A 4-km explicit convection simulation using Smagorinsky subgrid mixing in the vertical and horizontal dimensions exhibits the best MJO strength and propagation speed. Explicit convection simulations at $12 \mathrm{~km}$ also perform much better than the 12-km parameterized convection run, suggesting that the convection scheme, rather than horizontal resolution, is key for these MJO simulations. Interestingly, a 4-km explicit convection simulation using the conventional boundary layer scheme for vertical subgrid mixing (but still using Smagorinsky horizontal mixing) completely loses the large-scale MJO organization, showing that relatively high resolution with explicit convection does not guarantee a good MJO simulation. Models with a good MJO representation have a more realistic relationship between lower-free-tropospheric moisture and precipitation, supporting the idea that the moisture-convection feedback is a key process for MJO propagation. There is also increased generation of available potential energy and conversion of that energy into kinetic energy in models with a more realistic MJO, which is related to larger zonal variance in convective heating and vertical velocity, larger zonal temperature variance around $200 \mathrm{hPa}$, and larger correlations between temperature and ascent (and between temperature and diabatic heating) between 500 and $400 \mathrm{hPa}$.
\end{abstract}

\section{Introduction}

Perhaps the most fundamental challenge in tropical meteorology and climate is to understand the complex interactions between phenomena at many different time and space scales. Key phenomena exist at scales ranging from microscales (ice pellets, snowflakes, and raindrops) through convective scales (updrafts, downdrafts, and

\footnotetext{
* Supplemental information related to this paper is available at the Journals Online website: http://dx.doi.org/10.1175/JAS-D-120227.s1.

Corresponding author address: Christopher E. Holloway, Department of Meteorology, University of Reading, Earley Gate, P.O. Box 243, Reading RG6 6BB, United Kingdom.

E-mail: c.e.holloway@reading.ac.uk
}

clouds), mesoscales (squall lines and rainfall bands), and synoptic scales (equatorial waves, tropical cyclones, and monsoon troughs) to planetary scales [the Hadley circulation, the Walker circulations, and the MaddenJulian oscillation (MJO)].

The MJO is the dominant form of intraseasonal (2080 days) variability in the tropics. It consists of an envelope of convective activity near the equator with an approximate spatial scale of a few thousand kilometers that propagates eastward about $5 \mathrm{~m} \mathrm{~s}^{-1}$ over the IndoPacific warm pool, with a faster-propagating uppertropospheric wave pattern, likely a Kelvin wave response, continuing eastward around the rest of the equatorial belt (Madden and Julian 1994). The coupling between small-scale convective motions, mesoscale convective clusters, and the planetary-scale waves appears to be fundamental to the MJO (e.g., Majda and Biello 2004). 
Several processes have been proposed in the literature as being important for MJO strength and propagation. Moisture-convection feedbacks are strongly linked to MJO propagation within the Indian and western Pacific Ocean basins in studies using both observations (e.g., Maloney and Hartmann 1998; Kiladis et al. 2005; Tian et al. 2006) and numerical and conceptual models (e.g., Hannah and Maloney 2011; Grabowski and Moncrieff 2004), leading some to refer to the MJO as a "moisture mode" linked to changes in tropospheric humidity that cannot be captured by any dry atmospheric dynamical mode (e.g., Neelin and Yu 1994; Fuchs and Raymond 2002; Majda and Stechmann 2009; Sobel and Maloney 2012). Radiation feedbacks are found to be important in some modeling studies (Fuchs and Raymond 2002). Surface flux feedbacks are also thought to be important, although they tend to lag the center of active convection and therefore should slow the propagation speed (Sobel et al. 2008, 2010). Another mechanism that may be important for MJO maintenance and propagation is convective momentum transport (e.g., Majda and Biello 2004; Liu and Moncrieff 2004; Majda and Stechmann 2009; Miyakawa et al. 2012).

Global climate models (GCMs) must parameterize the rainfall and heating due to convective processes based on the large-scale prognostic variables, typically at grid lengths of $1^{\circ}$ latitude-longitude. These models usually struggle to get $\mathrm{MJO}$ variability that is as strong as observed and that propagates over a large enough horizontal extent (Lin et al. 2006; Kim et al. 2011). The ability of GCMs to simulate realistic MJO variability is sensitive to model physics, particularly to the entrainment and detrainment rates and the rate of evaporation of condensate in the convective parameterizations, suggesting a strong link between the MJO and moistureconvection feedbacks (Lin et al. 2006; Kim et al. 2011).

Until recently, it has not been possible to explicitly simulate the planetary and convective scales simultaneously. However, the Nonhydrostatic Icosahedral Atmospheric Model (NICAM) has produced fairly realistic simulations of a few MJO cases in terms of cloud, precipitation, and zonal wind using a global model with explicit convection at grid spacings of 14,7 , and $3.5 \mathrm{~km}$ (Miura et al. 2007; Nasuno et al. 2009; Liu et al. 2009; Oouchi et al. 2009; Taniguchi et al. 2010; Miyakawa et al. 2012). Another approach has been the multiscale modeling framework (MMF, or superparameterization) in which a GCM with a coarse large-scale grid uses 2D cloud-system resolving models (CSRMs) embedded in each grid cell to explicitly simulate local convection based on the large-scale prognostic variables and then outputs the large-scale mean properties back to the coarse grid (Grabowski and Smolarkiewicz 1999;
Khairoutdinov and Randall 2001). This framework has also shown improvement in the MJO (or in MJO-like variability in aquaplanet configurations) for both atmosphere-only simulations (Grabowski 2003; Benedict and Randall 2009) and especially for coupled oceanatmosphere simulations (Benedict and Randall 2011). In a limited-area (although zonally periodic) framework, Shutts (2006) and Shutts (2008) find persistent eastward-propagating large-scale precipitation clusters in an equatorial beta-plane simulation of tropical convection using explicit convection on an anisotropic grid with $1-\mathrm{km}$ spacing in the zonal direction and $40-\mathrm{km}$ spacing in the meridional direction.

Here we utilize the ability of the Met Office Unified Model to run with the same dynamic core for very different resolutions over the same limited area. This allows us to make a direct comparison between simulations at different horizontal and vertical resolutions and using different parameterizations of convection and subgrid mixing. The limited-area modeling framework reduces computation costs and allows for fairly consistent conditions at the lateral boundaries of the region of interest.

The simulations discussed in this paper have been run and analyzed as part of "Cascade," a project that seeks to better understand the interaction between tropical convection at the cloud-system-scale and larger-scale processes including the MJO, the diurnal cycle of convection over land (Pearson et al. 2010; Love et al. 2011), easterly waves, and equatorially trapped waves. To achieve this goal, Cascade employs high-resolution CSRM simulations of the Met Office Unified Model (UM) over very large tropical domains and compares them with high-resolution observations [such as data from the African Monsoon Multidisciplinary Analyses (AMMA) for the West Africa domain simulations], operational analyses provided for the Year of Tropical Convection (YOTC; Waliser et al. 2008, 2012), and simulations of the same model using parameterized convection. A previous paper (Holloway et al. 2012) looked at the same simulations discussed in the present study but focused on the different precipitation distributions and the vertical structure within different rainfall regimes.

We explain the setup of the model simulations in section 2 and describe the observational data and operational analyses in section 3 . In section 4 , we compare the different model simulations to observations and operational analyses for large-scale organization and $\mathrm{MJO}$ characteristics, including a principal component analysis based on Wheeler and Hendon (2004). A comparison of the vertical structure of the circulation is presented in section 5. In section 6 we discuss the relationship between humidity and precipitation in the different models and 
European Centre for Medium-Range Weather Forecasts (ECMWF) operational analysis. We present an analysis of the energetics of the MJO analogous to parts of the Lorenz energy cycle in section 7 , followed by a summary and discussion in section 8 .

\section{Model setup}

As described in Holloway et al. (2012), we use the limited-area mode of version 7.1 of the Met Office UM (Davies et al. 2005), which is semi-Lagrangian and nonhydrostatic; our limited-area runs are updated at the lateral boundaries by ECMWF operational analyses. The initial conditions also come from an ECMWF forecast analysis (except for UM SST analysis, which is fixed at the initial value). The simulations all start at 0000 UTC 6 April 2009 and run for 10 days, part of YOTC MJO Case D (Waliser et al. 2012). The 40- and $12-\mathrm{km}$ horizontal grid model runs are updated directly from the ECMWF analyses every $6 \mathrm{~h}$ at the lateral boundaries via a "rim" of eight model grid points within which the prognostic fields are blended linearly between the interior model domain and the exterior analysis. The $4-\mathrm{km}$ grid runs are updated every $30 \mathrm{~min}$ from lateral boundary conditions computed from the $12-\mathrm{km}$ parameterized convection run (12-km param). The rim points are excluded from the domain for the purposes of scientific analysis. The $12-\mathrm{km}$ domain is approximately $21^{\circ} \mathrm{S}-21^{\circ} \mathrm{N}, 41^{\circ} \mathrm{E}-178^{\circ} \mathrm{W}$, the $4-\mathrm{km}$ domain is set about $1^{\circ}$ inside of this on all four sides, and the 40-km domain is similar to the 12-km domain except that its eastern limit is about $3.5^{\circ}$ farther west.

Within the rim, prognostic variables from the freely evolving inner domain are nudged toward the specified analysis lateral boundary conditions at the outer edge of the rim, with contributions from the two sources weighted linearly across the eight points so that in the middle of the rim the two sides are weighted equally. This means that the lateral boundary conditions seen by the model at the outer edge of its interior domain partly depend on that domain itself, so that there can be feedbacks in which, for instance, greater low-level convergence and upper-level divergence in the model interior lead to greater low-level inflow and upper-level outflow in the rim itself and allow for greater moisture convergence and ventilation, which can help to sustain more large-scale heating and ascent in the interior. This can lead to different domain-mean behavior in different model runs even though they share the same lateral boundary conditions.

In addition to differences in horizontal grid spacing, there are more vertical levels in the 4-km runs (70 levels) than in the 12- and 40-km runs (38 levels) with the model top around $40 \mathrm{~km}$ high in both cases. Vertical spacing between levels ranges from tens of meters in the boundary layer to around $250 \mathrm{~m}$ in the free troposphere for the 4-km models and approximately double this for the 12- and $40-\mathrm{km}$ models. The vertical levels are terrainfollowing hybrid heights.

The model-physics settings differ among the runs as follows: the $12-\mathrm{km}$ param model uses a modified GregoryRowntree convective parameterization [with convective available potential energy (CAPE) as the basis for its closure; Gregory and Rowntree 1990] with 30-min CAPE relaxation time scale, as well as an adjustment to reduce this at very high vertical velocity in order to prevent gridpoint storms. The standard boundary layer scheme (Lock et al. 2000) is used for vertical subgrid mixing, and there is no horizontal subgrid mixing. There is a singlemoment mixed-phase microphysics scheme with two components: ice/snow and liquid water (Wilson and Ballard 1999); rainfall is diagnosed at each time step, although reevaporation of rainfall is included. The $40-\mathrm{km}$ model is similar to the $12-\mathrm{km}$ param model except that the convective parameterization has a CAPE relaxation time scale that is reduced at larger relative humidity rather than at high vertical velocity. The 4-km 2Dsmag model uses a CAPE-limited version of the convective parameterization that asymptotically approaches the same 30-min CAPE time scale at zero CAPE but has a CAPE time scale that rapidly increases with increasing CAPE such that for typical tropical values, virtually all rainfall is generated explicitly (Roberts 2003; Lean et al. 2008). This model version uses the standard boundary layer scheme for vertical subgrid mixing but includes Smagorinsky-type subgrid mixing in the horizontal dimensions. The Smagorinsky eddy viscosity is parameterized as $\nu=\left(c_{s} \Delta\right)^{2} S f\left(\mathrm{Ri}_{p}\right)$, where $\Delta$ is the horizontal grid length, $c_{s}$ is set to $0.1, S$ is based on the modulus of the rate of strain tensor $\mathbb{S}_{i j}$ such that $S=\left\|\mathbb{S}_{i j}\right\| / \sqrt{2}$, and $f\left(\mathrm{Ri}_{p}\right)$ is an extension to the classical Smagorinsky-Lilly approach, which takes account of the dynamic effects of the local Richardson number on viscosity. Smagorinsky mixing is commonly used in CSRMs at similar resolutionsfor example, at 3-km grid spacing in the System for Atmospheric Modeling (SAM) in Bretherton et al. (2004). The microphysics scheme now has prognostic rain in addition to the two components in the version above. The 4-km 3Dsmag model also uses the CAPE-limited convective parameterization but uses Smagorinsky mixing in all three dimensions, including the vertical (still using the horizontal grid length in the viscosity formulation as above), and therefore it does not use the boundary layer scheme. The microphysics settings are the same as those in the other $4-\mathrm{km}$ version. The $12-\mathrm{km}$ 3Dsmag model and the 12-km 2Dsmag model use the CAPE-limited 
TABLE 1. Main differences in the six model configurations used. "Smagorinsky" refers to the Smagorinsky-Lilly-type turbulence scheme used in some of the model versions, and "boundary layer" refers to the standard boundary layer subgrid mixing scheme.

\begin{tabular}{lcclcc}
\hline \hline & $\begin{array}{c}\text { Horizontal grid } \\
\text { spacing }(\mathrm{km})\end{array}$ & $\begin{array}{c}\text { Vertical } \\
\text { levels }\end{array}$ & Convection & Horizontal subgrid mixing & Vertical subgrid mixing \\
\hline $40 \mathrm{~km}$ & 40 & 38 & Parameterized & None & Boundary layer \\
12-km param & 12 & 38 & Parameterized & None & Boundary layer \\
12-km 3Dsmag & 12 & 38 & Explicit & Smagorinsky & Smagorinsky \\
12-km 2Dsmag & 12 & 38 & Explicit & Smagorinsky & Boundary layer \\
4-km 3Dsmag & 4 & 70 & Explicit & Smagorinsky & Smagorinsky \\
4-km 2Dsmag & 4 & 70 & Explicit & Smagorinsky & Boundary layer \\
\hline
\end{tabular}

convective parameterization as well, with turbulence mixing parameterized as in the analogous $4-\mathrm{km}$ model versions; the microphysics settings are the same as those in the 4-km models. These two 12-km model simulations have been performed in order to test the effects of explicit versus parameterized convection at the same horizontal resolution and keeping the same physics and mixing settings for consistency in comparison with the other model runs; even though there are physical reasons to doubt the fidelity of a model using explicit convection and Smagorinsky turbulence mixing at such coarse grid spacing, we believe that there are scientific insights to be gained from such experiments. The six model versions and their main differences are summarized in Table 1.

\section{Data}

We use Tropical Rainfall Measuring Mission (TRMM) 3B42 merged satellite rainfall data, with $0.25^{\circ}$ latitudelongitude resolution and 3-h temporal resolution (Huffman et al. 2007) to calculate rainfall Hovmöller plots and time series averaged in regions near the equator.

ECMWF operational analyses, which are at approximately $25-\mathrm{km}$ grid spacing in the tropics and archived for the YOTC, are used to compare to model simulations and also as lateral boundary conditions for the limitedarea model runs. As described in Holloway et al. (2012), we have found that ECMWF column water vapor agrees well with TRMM Microwave Imager (TMI) column water vapor data over the period. Note that, to match the data sources used for similar calculations in Wheeler and Hendon (2004), we have used National Centers for Environmental Prediction-National Center for Atmospheric Research (NCEP-NCAR) reanalysis data (Kalnay et al. 1996) along with interpolated outgoing longwave radiation (OLR) data at $2.5^{\circ}$ from the National Oceanic and Atmospheric Administration (NOAA) Climate Prediction Center (CPC) (Liebmann and Smith 1996) to calculate limited-area empirical orthogonal functions (EOFs) and principal components.
We generate high-resolution (nominally $4 \mathrm{~km}$ ) OLR data from window-channel $(\sim 10.7 \mu \mathrm{m})$ infrared (IR) data merged by CPC from several geostationary satellites (Janowiak et al. 2001), which is also used in the TRMM merged rainfall algorithm mentioned above, for the OLR animation in the supplemental material. To convert from narrowband IR to OLR we calculate a flux-equivalent brightness temperature following Ohring et al. (1984) and then use this as a blackbody temperature in the Stefan-Boltzmann law.

\section{MJO comparison: Overall strength and propagation speed}

In this section we assess the overall MJO behavior in the model simulations, focusing on precipitation and a principal component analysis of OLR and zonal wind at 850 and $200 \mathrm{hPa}$ similar to Wheeler and Hendon (2004).

\section{a. Precipitation}

Figure 1 shows Hovmöller plots for TRMM precipitation and six of the model simulations averaged between $7.5^{\circ} \mathrm{S}$ and $7.5^{\circ} \mathrm{N}$ for the 10 -day period with time increasing upward. The period is part of YOTC MJO Case D as described in Waliser et al. (2012). The eastward-propagating envelope of convection associated with the MJO is clearly evident in the TRMM data, consisting largely of a convectively coupled Kelvin wave that moves ahead of the main MJO signal (as defined using an empirical index below) into the western Pacific by the end of the period, as mentioned in Waliser et al. (2012), along with embedded precipitation clusters that appear to be moving mainly westward. Some of the most intense precipitation events appear to be associated with the intersection of equatorially trapped Kelvin and Rossby waves (Waliser et al. 2012)

Comparing the six model runs and the TRMM data in Fig. 1, the most obvious difference lies between the two models using parameterized convection (the $40-\mathrm{km}$ 

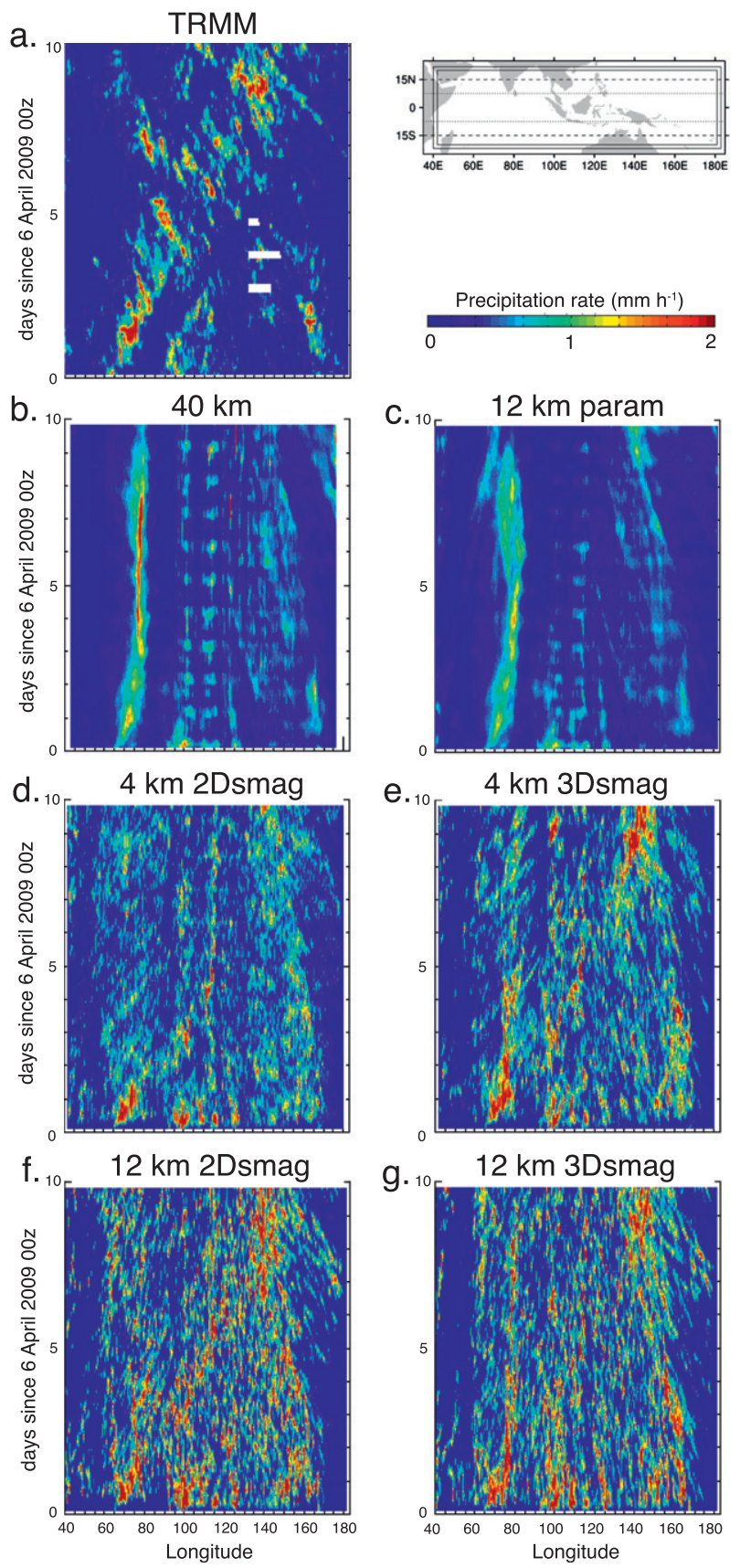

FIG. 1. Hovmöller plots (with time increasing upward) of precipitation $\left(\mathrm{mm} \mathrm{h}^{-1}\right)$ averaged between $7.5^{\circ} \mathrm{S}$ and $7.5^{\circ} \mathrm{N}$ and in $3-\mathrm{h}$ periods for six Cascade runs and TRMM merged precipitation data for 10 days starting 6 Apr 2009. Horizontal averaging in the zonal direction is done at $25 \mathrm{~km}$ for TRMM and $24 \mathrm{~km}$ for the model runs (with the exception of the 40-km model, which is left at its original $40-\mathrm{km}$ grid spacing). White regions are missing TRMM data. Map shows the 12-km domain (larger box) and 4-km domain (smaller box); the $40-\mathrm{km}$ domain is similar to the $12-\mathrm{km}$ domain except that the eastern limit is about $3.5^{\circ}$ farther west. Horizontal lines on the map show Hovmöller limits for most plots (dotted) and PC analysis (dashed). model and the $12-\mathrm{km}$ param model) and the other four models, which use explicit convection. The parameterized convection models show significantly fewer areas of very strong convection, and their convective regions show little eastward propagation. In the Maritime Continent, convection is dominated by the diurnal cycle, with the main equatorial land regions, especially Sumatra and Borneo, showing precipitation shortly after sunrise at their respective longitudes (Love et al. 2011). The convection in the central Indian Ocean retains its organized nature in both models for the 10-day period, but it does not move into the Maritime Continent. The 12-km param model does, however, appear to partly capture the final flareup of convection around $140^{\circ}-$ $145^{\circ} \mathrm{E}$; the $40-\mathrm{km}$ model is the only model that does not capture this feature at all. This flareup appears to be part of the convectively coupled Kelvin wave mentioned above, but it has also possibly been triggered by a westwardmoving disturbance propagating from around $160^{\circ} \mathrm{E}$ at day 5 (11 April) and also corresponds with a fasterpropagating disturbance moving westward from the eastern edge of our domain starting around day 7 (13 April).

The four explicit convection model runs (Figs. 1d-g) all exhibit organized clusters of convection that are more variable in size and intensity, less stationary with respect to longitude, and less strongly diurnally varying than the convective clusters in the parameterized convection models. These clusters appear to move both eastward and westward, similar to TRMM to an extent, although there is less obvious westward propagation in the models. The strongest of these clusters have similar magnitudes to the strongest TRMM clusters, although the explicit convection models actually have too much rainfall and too many areas with rainfall at a given time. In fact, the domain-mean rainfall is significantly larger than TRMM for all models, especially the explicit convection models, as discussed in Holloway et al. (2012) and shown in their Fig. 1. This is partly due to a feedback between initially heavier rain during spinup, increased lower-level convergence and upper-level divergence in the domain as a whole, and lateral boundary conditions that are blended with this internal circulation (cf. Holloway et al. 2012).

Three of the four explicit convection models also capture the eastward-propagating large-scale convective envelope. The only explicit convection model that loses this large-scale organization is the 4-km 2Dsmag model, although it does show some eastward propagation in the Indian Ocean, which is faster than that observed, for the first 4 days. This model has many areas of convection spread across many longitudes, with less largescale organization in general. The poor performance 


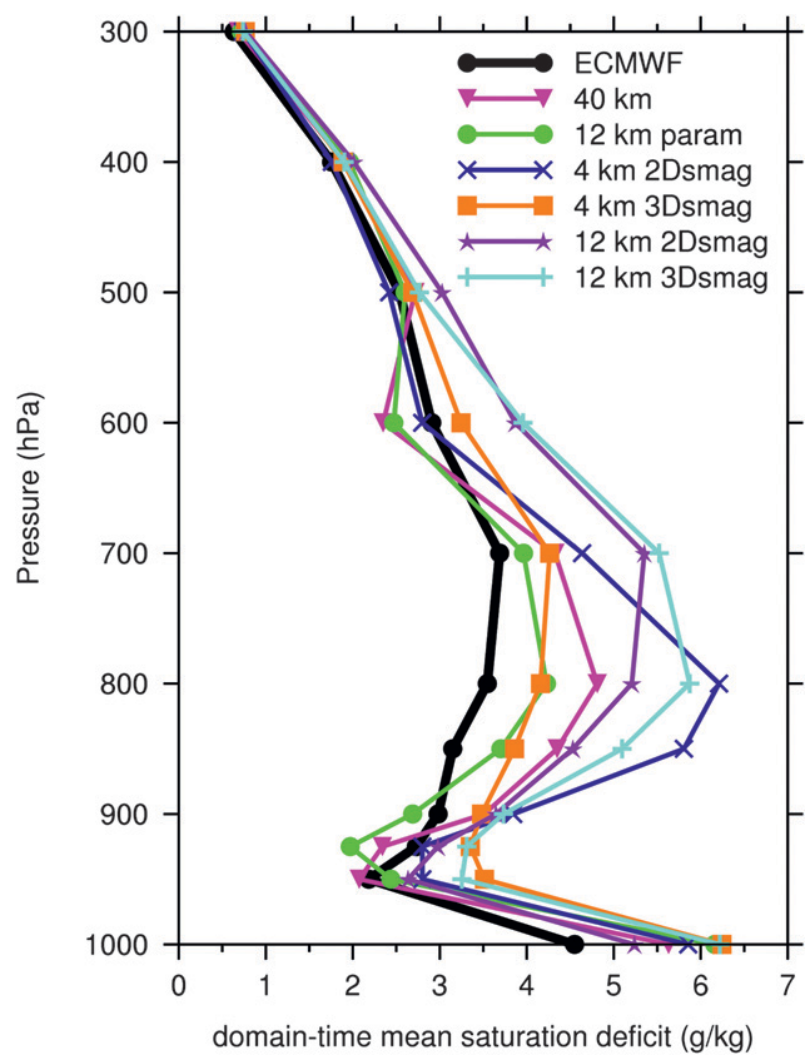

FIG. 2. Mean saturation deficit $\left(\mathrm{g} \mathrm{kg}^{-1}\right.$ ) (for each model/analysis, over entire equatorial region $7.5^{\circ} \mathrm{S}-7.5^{\circ} \mathrm{N}$ and 10 -day period, at each level) for ECMWF operational analyses and five Cascade runs for the 10-day case study.

of the 4-km 2Dsmag model relative to the 4-km 3Dsmag model must be related to the vertical subgrid mixing. The 3D Smagorinsky mixing does lead to a moister lower troposphere above the boundary layer in the 4-km 3Dsmag model compared to the 4-km 2Dsmag, as seen in Fig. 2, which shows the mean saturation deficit $\left(q_{s}-q\right.$, the saturation specific humidity minus the actual specific humidity) for each model averaged over all longitudes and $7.5^{\circ} \mathrm{S}-7.5^{\circ} \mathrm{N}$ over the entire period for each level and model or analysis. One reason for this is that the boundary layer scheme was originally designed to act alongside the convective parameterization, so that in convective boundary layers the nonlocal scheme mixed only between the surface and just below the lifted condensation level (LCL). The local boundary layer scheme can still mix at levels that are not adjacent to the LCL, but the local effective mixing length is $40 \mathrm{~m}$, which is about an order of magnitude smaller than that of the 3Dsmag models. This will be discussed more in a future paper. Note that the $12-\mathrm{km} 2 \mathrm{Dsmag}$ model does not share the same problems with maintaining large-scale organization and $\mathrm{MJO}$ propagation as the 4-km 2Dsmag model, despite also having a fairly dry lower tropopshere, which it shares with the $12-\mathrm{km}$ 3Dsmag model. This may be because the $12-\mathrm{km}$ explicit convection models are forced to resolve convection at such a coarse scale that there is relatively more suppression of convection in regions with suppressed convection in the observations, which would lead to more realistic differences between suppressed and active regions and a stronger, more realistic MJO.

The 12-km 3Dsmag and 12-km 2Dsmag models look much more similar to the 4-km 3Dsmag models than to the $12-\mathrm{km}$ param model, illustrating the importance of the representation of convection, rather than horizontal resolution per se, in simulating the organization and propagation of large-scale convection in this study. We would expect that explicit convection would improve with finer horizontal resolution, and indeed the 4-km 3Dsmag model has slightly less mean rainfall than the two 12-km explicit convection models, although it is still too high relative to observations, as mentioned above. Also, the 4-km 3Dsmag model has slightly more realistic patterns of convection within the eastward-propagating envelope. The $12-\mathrm{km} 2 \mathrm{Dsmag}$ model has very active convection for almost the entire length of the convective envelope, unlike TRMM.

The OLR animation in the supplemental material shows OLR calculated from merged CPC IR data (nominally 4-km resolution) along with OLR from the 4-km 3Dsmag and $12-\mathrm{km}$ param models at their original horizontal resolutions, all using 3-hourly instantaneous values for the 10-day period. Although OLR is not a perfect proxy for precipitation, many features in Figs. 1a,c,e can be understood in more detail from this animation. For instance, the diurnal cycle over the islands of the Maritime Continent is much more regular, and the convection is much more confined to the land regions, in the $12-\mathrm{km}$ param model. Related to this, there is much less convection propagating off of Sumatra to the west into the eastern equatorial Indian Ocean in this model compared with observations. The 4-km 3Dsmag does have convection propagating from Sumatra into this region, although it too develops a relatively suppressed region (higher OLR and less rainfall) between about $85^{\circ}$ and $95^{\circ} \mathrm{E}$. The animation also reveals the difference in the character of the OLR fields, with the satellite OLR showing more large clusters of cold cloud tops and fewer small isolated clusters relative to the 4-km 3Dsmag, which has some large regions of mostly cold cloud tops but has more "blobs" of low OLR both within these convective regions and scattered at the peripheries. These large (of order $100 \mathrm{~km}$ in this case) somewhat circular blobs of high clouds are a common feature of models with explicit convection with grid spacing on the 
order of $1 \mathrm{~km}$ or larger, which is still not fine enough to resolve deep convection at the scales it exhibits in nature (this may seem counterintuitive since satellite OLR appears to have more large clusters and fewer small ones, but it may be that the lack of explicit representation of very small scales even in the explicit convection models prohibits sufficient large-scale organization and/ or sufficient suppression of isolated areas of deep convection). The $12-\mathrm{km}$ param model has large regions of moderate OLR that appear to show less variability and evolution over the period than either the observations or the 4-km 3Dsmag model. This is consistent with Holloway et al. (2012), which found that the $12-\mathrm{km}$ param has rainfall that is too light and covers too large an area relative to TRMM.

\section{b. Principal component index using zonal wind and $O L R$}

To compare the large-scale strength and propagation of the MJO in the model simulations to observations in an objective manner, we have performed a principal component analysis similar to that of Wheeler and Hendon (2004, hereafter WH04). However, because our simulations are on a limited domain, we have calculated new limited-area EOFs using longitudes $45^{\circ}-175^{\circ} \mathrm{E}$, inclusive, averaged from latitudes $15^{\circ} \mathrm{S}-15^{\circ} \mathrm{N}$, of the $2.5^{\circ}$ NCEP-NCAR reanalysis data and gridded, interpolated OLR data from NOAA/CPC. The EOFs have been calculated from the 30 years from 1980 to 2009 using daily anomalies (we have removed the first three harmonics of the seasonal cycle of the 30 years, as well as the mean of the previous 120 days, as in WH04). Figure 3 shows the new EOFs compared with the original ones. Note that our EOFs for principal components 1 (PC1) and 2 (PC2) correspond with WH04's EOFs for realtime multivariate MJO series 2 (RMM2) and 1 (RMM1), respectively. These two EOFs account for $21 \%$ and $20.2 \%$ of the total variance (and are well separated from the third EOF, which represents only $7.1 \%$ ), similar to those of $\mathrm{WH} 04$, and the two principal components show similar lag correlations as well, suggesting that they can still capture MJO activity at a similar level to the fulldomain principal components.

To calculate the principal components from the model output, we first remove the same three harmonics of the seasonal cycle for the 30 years of NCEP-NCAR reanalysis winds and NOAA/CPC OLR, as well as the mean of the previous 120 days of these datasets. We then standardize these anomalies by dividing by standard deviations also calculated from these datasets, which are the same standard deviations used to normalize the data used to compute our limited-area EOFs. We use these values because we have only these short initialized
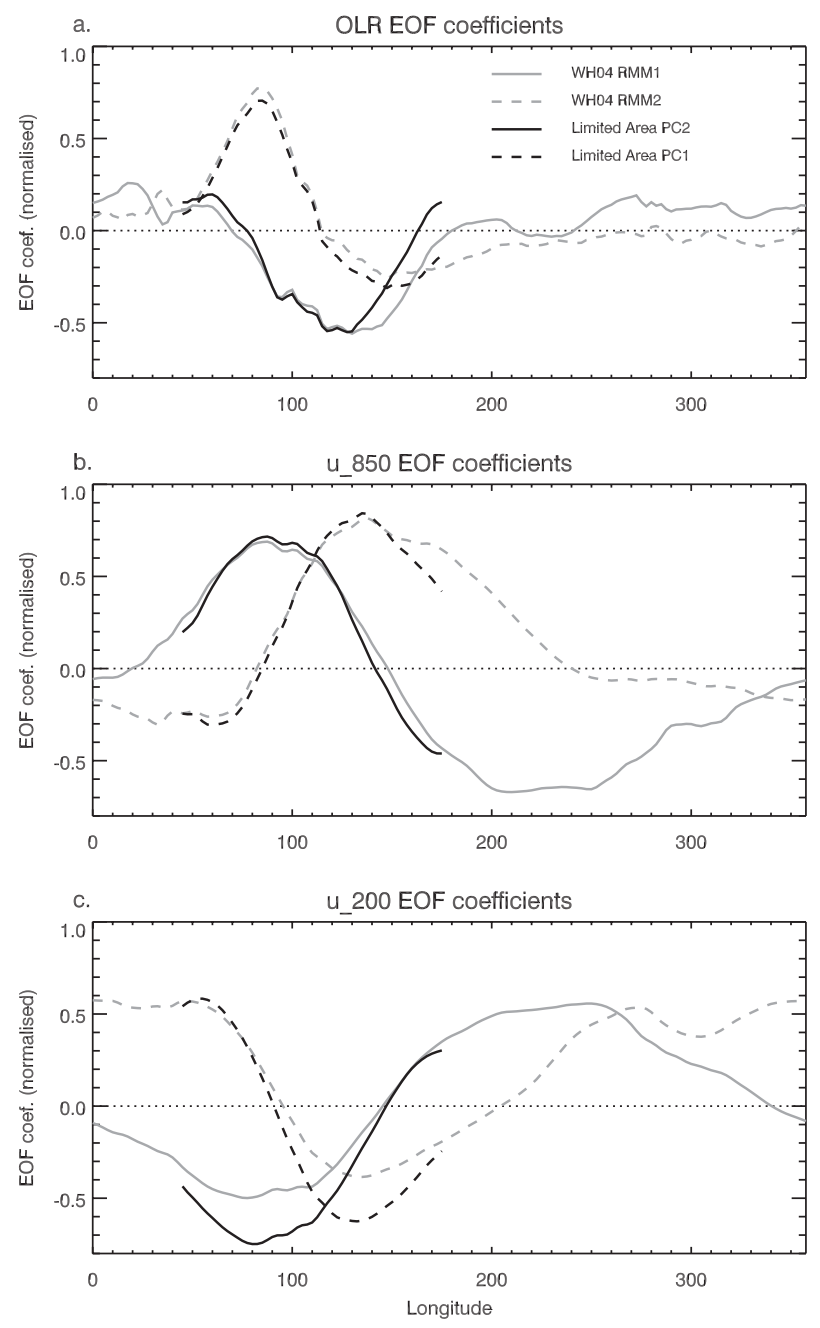

FIG. 3. EOF coefficients for the full domain as calculated in WH04 (gray) and those calculated for the limited domain in this study (black) for (a) OLR, (b) zonal wind at $850 \mathrm{hPa}$, and (c) zonal wind at $200 \mathrm{hPa}$. Note that our PC1 and PC2 correspond to their RMM2 and RMM1, respectively.

model runs, so we have no better estimate of a model climatology or mean variance. This approach should at least make for a consistent comparison between models and reanalysis/observations.

Figure 4 shows the six model versions for the 10-day period compared with observations from NCEP-NCAR reanalysis (and NOAA/CPC OLR) over the whole month of April 2009. We use NCEP-NCAR reanalysis for winds, rather than ECMWF operational analyses, because these were used by WH04 and in this study to calculate the EOFs; however, the equivalent 10-day curve for the ECMWF operational analyses (not shown) is very similar to the NCEP-NCAR curve, with a slight shift of about +0.3 for PC 2 and -0.1 for $\mathrm{PC} 1$ on average and with virtually the same shape. The 4-km 3Dsmag 


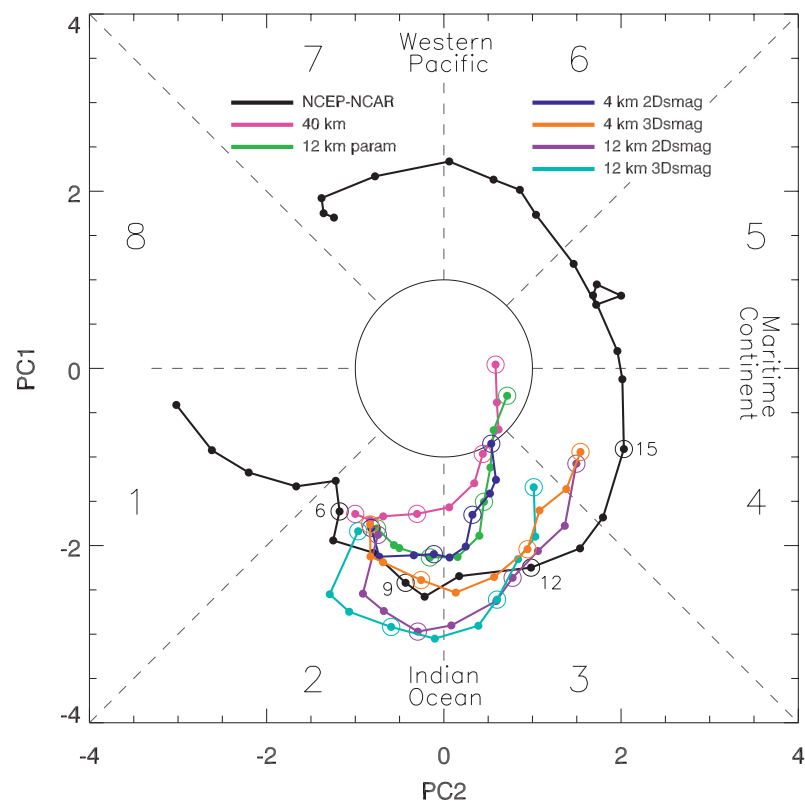

FIG. 4. MJO phase diagram for NCEP-NCAR reanalysis (and NOAA/CPC OLR) for all of April 2009 and for six Cascade runs for 10 days starting 6 Apr 2009. Principal components are calculated from the limited-domain EOFs. Large circles are placed at 3-day intervals.

model performs best overall. The $12-\mathrm{km}$ explicit convection models (3Dsmag and 2Dsmag) actually show an MJO that is too strong in the beginning but overall better than the parameterized convection models $(40-\mathrm{km}$ and $12-\mathrm{km}$ param) and the 4-km 2Dsmag model. The latter three models all lose the MJO signal by the end of the 10-day simulation.

Figure 5 breaks down $\mathrm{PC} 1$ and $\mathrm{PC} 2$ into the three original fields (OLR and zonal wind at 850 and $200 \mathrm{hPa}$, referred to below as $u_{850}$ and $u_{200}$ ) that contribute to them (note that we do not show the 12-km 2Dsmag model in this figure for clarity because it shows no important differences from the 12-km 3Dsmag model). Changes in PC2 are the main contributors to propagation of the MJO from the Indian Ocean into the Maritime Continent, and so PC2 is the most relevant principal component for this case study period. For $\mathrm{PC} 2$, the meteorological component that changes most during the case in NCEP-NCAR is $u_{850}$, and while all models capture the trend in the $u_{850}$ component of PC2, the parameterized convection models do not show as large an amplitude after around day 5. The secondlargest meteorological component for $\mathrm{PC} 2, u_{200}$, is represented fairly well by all models except the 4-km 2Dsmag run, which almost completely loses the upperwind signal as its convection becomes unorganized on the larger scale.
Although changes in $\mathrm{PC} 1$ are less important to the propagation of the MJO in this case, $\mathrm{PC} 1$ also shows large deficiencies for the parameterized convection models. For $u_{850}$, the $40-\mathrm{km}$ and $12-\mathrm{km}$ param models end up with a signal that is slightly too small in amplitude in the last few days of the period. For $u_{200}$, they are even more deficient, being close to zero in the last 2 days. Note that the $12-\mathrm{km} 3$ Dsmag model is much too large in amplitude for $u_{850}$ for PC1, which explains why it has an overall amplitude that is too large in the middle of the period as shown in Fig. 4.

OLR contributes less than the two wind components to the amplitude of both PCs, and this is the case in general with the WH04 EOFs. However, in this case, the OLR signal is especially bad for the $40-\mathrm{km}$ model for $\mathrm{PC} 1$ and $\mathrm{PC} 2$, and OLR is the main reason that the $40-\mathrm{km}$ model has such a bad PC1 signal. Note that for the first 7 days, the OLR signal error partly cancels the error in the wind components (mainly $u_{850}$ ) for 4-km 3Dsmag and 12-km 3Dsmag models for PC1 and PC2, although this cancellation of errors is not the main reason that these three models have a better overall MJO in the full phase space of Fig. 4. It is somewhat puzzling that the OLR signal is so similar, and poor, for most of the models, despite their large differences in MJO signal by other metrics, including the precipitation Hovmöller plots in Fig. 1. Hovmöller plots of OLR (shown in the supplemental material, Fig. S1) suggest that the OLR signal in the 4-km 3Dsmag model over the Maritime Continent is too weak for the middle of the period despite strong precipitation there, which could mean that upper-level clouds and/or convective systems are not occupying a large enough area there. This is even more pronounced in OLR Hovmöller plots from $15^{\circ} \mathrm{S}$ to $15^{\circ} \mathrm{N}$, which is the latitude range used in this $\mathrm{PC}$ analysis, rather than $7.5^{\circ} \mathrm{S}-7.5^{\circ} \mathrm{N}$, which is used in all other parts of this paper including Fig. 1. Note also that the climatological seasonal cycle and previous-120-day mean, which are removed for each longitude to get OLR anomalies, comes from the observations, so it is possible that the 4-km 3Dsmag model mean OLR over the Maritime Continent would be higher than observed even if the model could be run for a much longer time, meaning that the model anomalies would be stronger if we had a model climatology available. The $40-\mathrm{km}$ model seems to suffer from a mean positive OLR bias relative to the other models and observations. Rainfall clusters during this time are also smaller in the 4-km 3Dsmag model than in observations, as can be seen in the OLR animation in the supplemental material.

The above analysis shows that the $12-\mathrm{km}$ param model suffers mainly from a wind signal that is too weak and that does not change enough, particularly for PC2 
PC 1
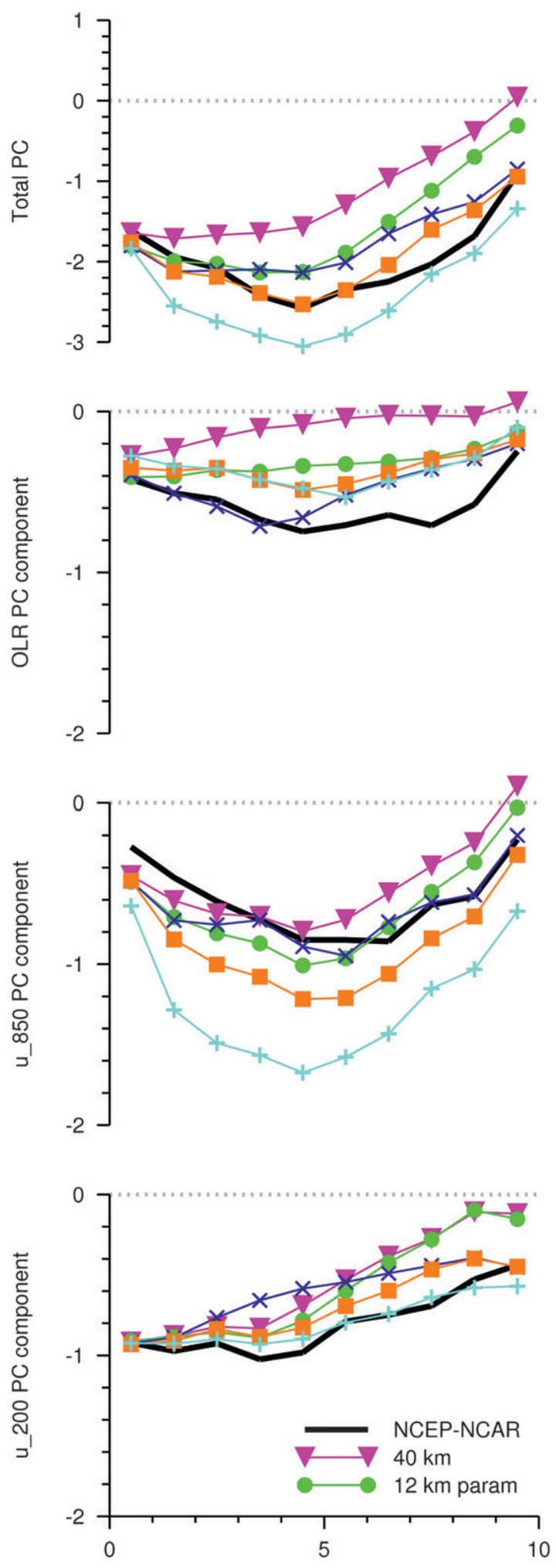

days since 6 April 2009 00z
PC 2
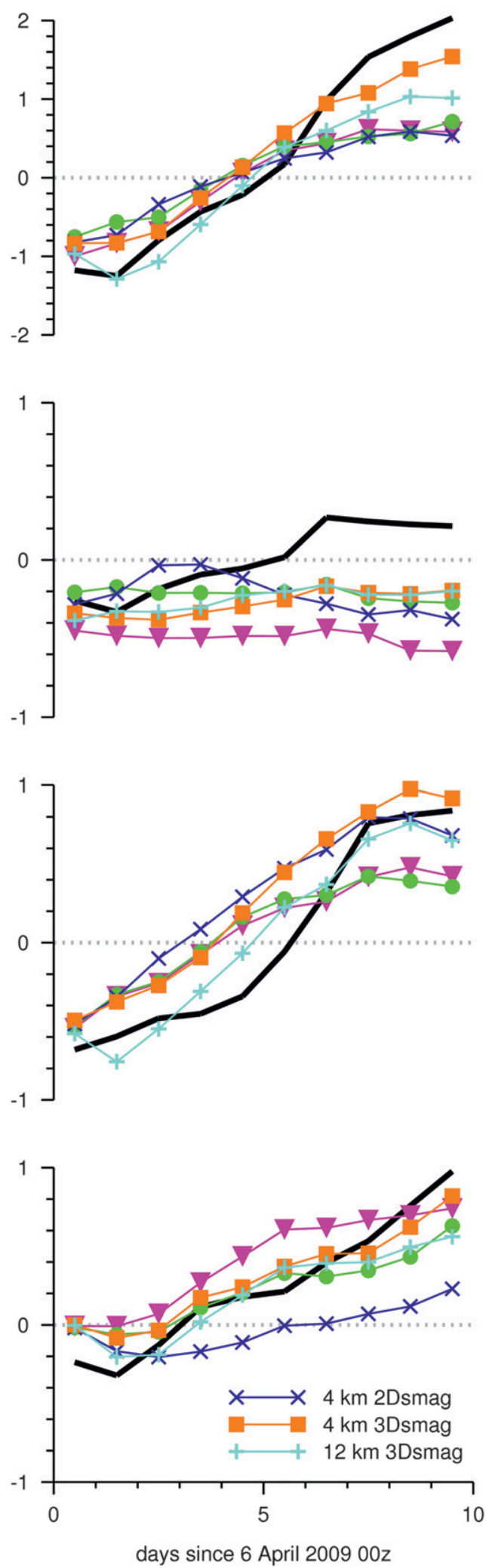

FIG. 5. MJO principal component meteorological subsets (OLR, 850-hPa zonal wind, and 200-hPa zonal wind) for several Cascade runs for 10 days starting 6 Apr 2009. 
(associated with convection which is organized but does not propagate). The $40-\mathrm{km}$ model has a similar problem, although it suffers additionally from an especially poor OLR signal. The 4-km 3Dsmag is the closest to observations overall, although some compensating errors are present, especially between zonal wind at $850 \mathrm{hPa}$ and OLR. The 12-km 3Dsmag model does maintain a strong, propagating $\mathrm{MJO}$ as seen in the observations, but it has a significantly larger amplitude in PC1 (and therefore in phase space as a whole) over most of the period, which is caused mainly by the zonal wind at $850 \mathrm{hPa}$.

\section{Vertical structure of winds}

Here we compare the different models and ECMWF operational analyses to see how the vertical structure of the MJO circulation is represented. We do not include the 12-km 2Dsmag model here because it is very similar to the $12-\mathrm{km}$ 3Dsmag model. Note that, although the ECMWF operational analyses will have wind fields, and particularly vertical velocities, that on small scales are largely influenced by the model's convective heating as diagnosed from its convection scheme, we believe that the large-scale vertical velocity shown in this section should be mainly determined by the assimilation of better-observed large-scale horizontal wind fields. That is why we include ECMWF vertical velocity here whereas this vertical velocity was not used as an observational comparison for a precipitation regime analysis on smaller scales in Holloway et al. (2012).

Figures 6-8 show the daily average pressure velocity and zonal wind (taken by averaging instantaneous values every $6 \mathrm{~h}$ ) for 7, 10, and 15 April, respectively, averaged on a $1^{\circ}$ longitude grid and averaged over $7.5^{\circ} \mathrm{S}-7.5^{\circ} \mathrm{N}$ for five Cascade models and ECMWF operational analysis. On 7 April, the second day of the case, Fig. 6 shows that all of the models have upward motion at the same longitudes that have significant upward motion in the ECMWF analysis. However, the explicit convection models actually have additional regions with upward motion, showing somewhat too-strong upward motion, related to too-strong precipitation, already. The $12-\mathrm{km}$ 3Dsmag model is particularly overactive. The $4-\mathrm{km}$ 3Dsmag model best captures the westward tilt of the main area of convection from $60^{\circ}$ to $80^{\circ} \mathrm{E}$, with more topheavy upward motion in the western part of the deep convective region, and with an accompanying westward tilt in the lower-level westerlies. The 4-km 2Dsmag model already has fewer concentrated regions of upward motion at this time, with lower-amplitude and lesshorizontally extensive local maxima of upward motion than in the other two explicit convection models and ECMWF. The 4-km 2Dsmag model has also begun to lose the upper-level easterlies around $85^{\circ}-95^{\circ} \mathrm{E}$ that are present in ECMWF and the other models. The parameterized convection models are much smoother in the horizontal, exhibiting less longitudinal variability in the amount of large-scale ascent. For instance, at midtropospheric levels from about 800 to $400 \mathrm{hPa}$, there is mainly weak ascent across most of the domain in the $40-\mathrm{km}$ and $12-\mathrm{km}$ param models except for areas of weak descent over the far western and eastern regions and a few areas of larger ascent in the main convective regions. In contrast, the explicit convection models and ECMWF operational analyses have more variability, including some negative values at more central longitudes between $60^{\circ}$ and $170^{\circ} \mathrm{E}$, at these midtropospheric levels. Instantaneous vertical velocities at this longitude grid graining (not shown) reveal that there are stronger downward motions near strong ascent in the explicit convection models and ECMWF that are generally not present in the parameterized convection models, leading to these differences in variability. This suggests that there are weaker dynamic responses to heating at these intermediate (several degrees of longitude) scales, or that the heating itself is much less spatially variable, in the parameterized convection models.

By the fifth day, 10 April, Fig. 7 shows that the most realistic model in terms of vertical and horizontal velocity pattern (as compared with ECMWF) is the 4-km 3Dsmag model, especially in terms of magnitude, zonal variability, and location of the main regions of ascent and descent. The ECMWF operational analyses show more shallow upward motion to the east and top-heavy upward motion to the west, as in observational studies of the MJO. Note the low-level easterlies undercutting the midlevel westerlies in the Indian Ocean in the parameterized convection models (although the other models have weaker westerlies at low levels). Also, the 4-km 2Dsmag model has lost any strong upper-level easterlies; this could be related to the lack of a strong eastwest gradient in deep upward motion, which in turn is likely due to a lack of large-scale convective organization (weakening of the MJO and its active and suppressed convective regions).

Figure 8 shows that by the last day, 15 April, most models have some development of organized ascent between $130^{\circ}$ and $150^{\circ} \mathrm{E}$, although it is much too weak in the case of the $12-\mathrm{km}$ param and 4-km 2Dsmag models, and it is missing almost entirely in the 40-km model.

Overall, the 4-km 3Dsmag model has the most realistic pattern of zonal and vertical velocity as compared with ECMWF, although it does not have as confined a region of large-scale ascent. The 12-km 3Dsmag model is also fairly realistic but suffers even more from the problem of too much ascent in some regions that should 

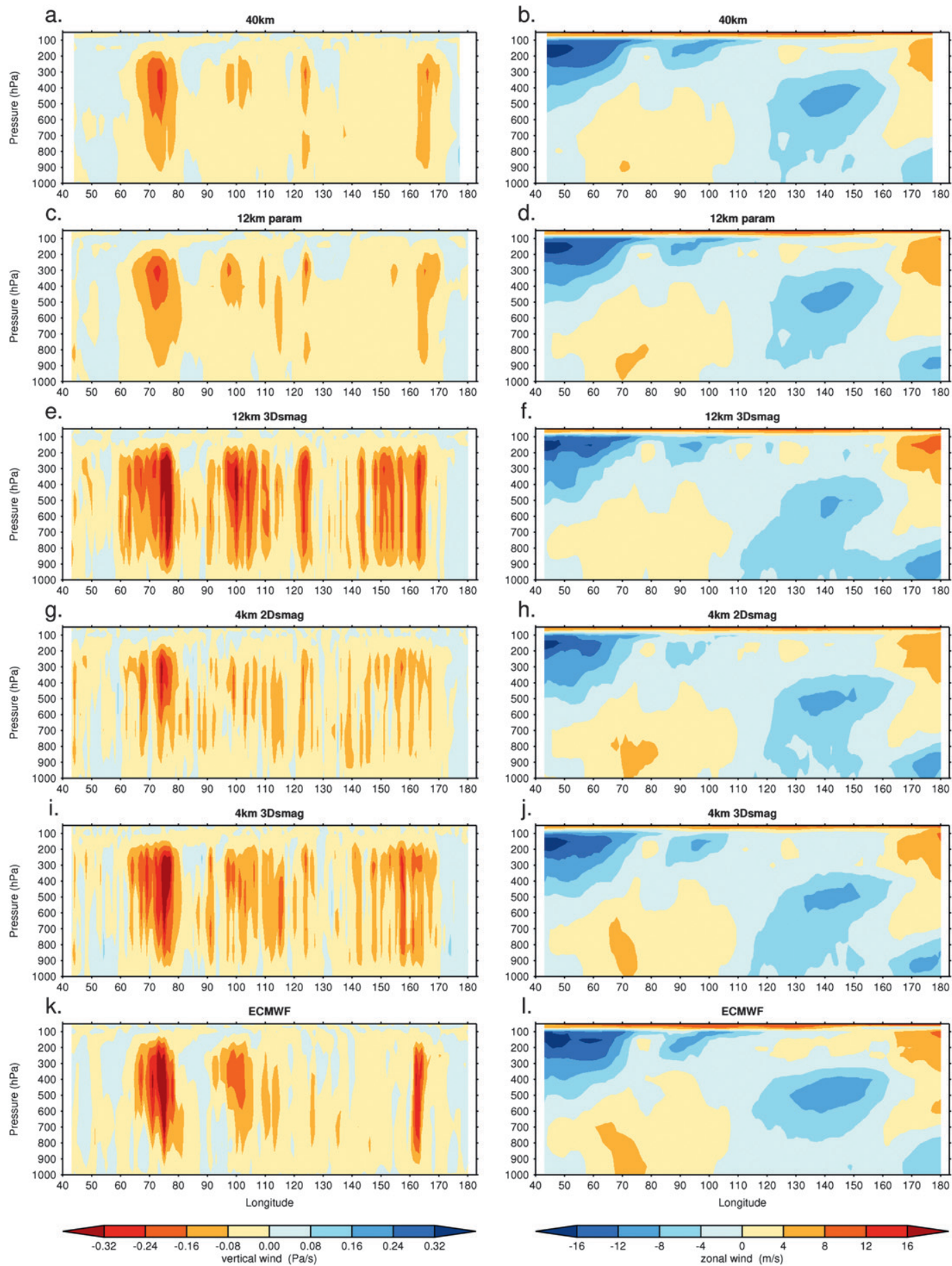

FIG. 6. Pressure velocity $\left(\mathrm{Pa} \mathrm{s}^{-1}\right)$ and zonal wind $\left(\mathrm{m} \mathrm{s}^{-1}\right)$ for five Cascade runs and ECMWF operational analyses daily average of four times for $7 \mathrm{Apr} 2009$ (0000, 0600,1200, and $1800 \mathrm{UTC}$ ), averaged between $7.5^{\circ} \mathrm{S}$ and $7.5^{\circ} \mathrm{N}$ and onto a $1^{\circ}$ longitude grid.

be more suppressed. The 4-km 2Dsmag model loses most of its large-scale organization in terms of vertical velocity and also has the weakest and least realistic upper-level easterlies of all the models, while the $12-\mathrm{km}$ param and 40-km models fail to propagate large-scale ascent eastward from the initial active region in the central Indian Ocean (although some ascent does form in the $12-\mathrm{km}$ param model and in the 4-km 2Dsmag 

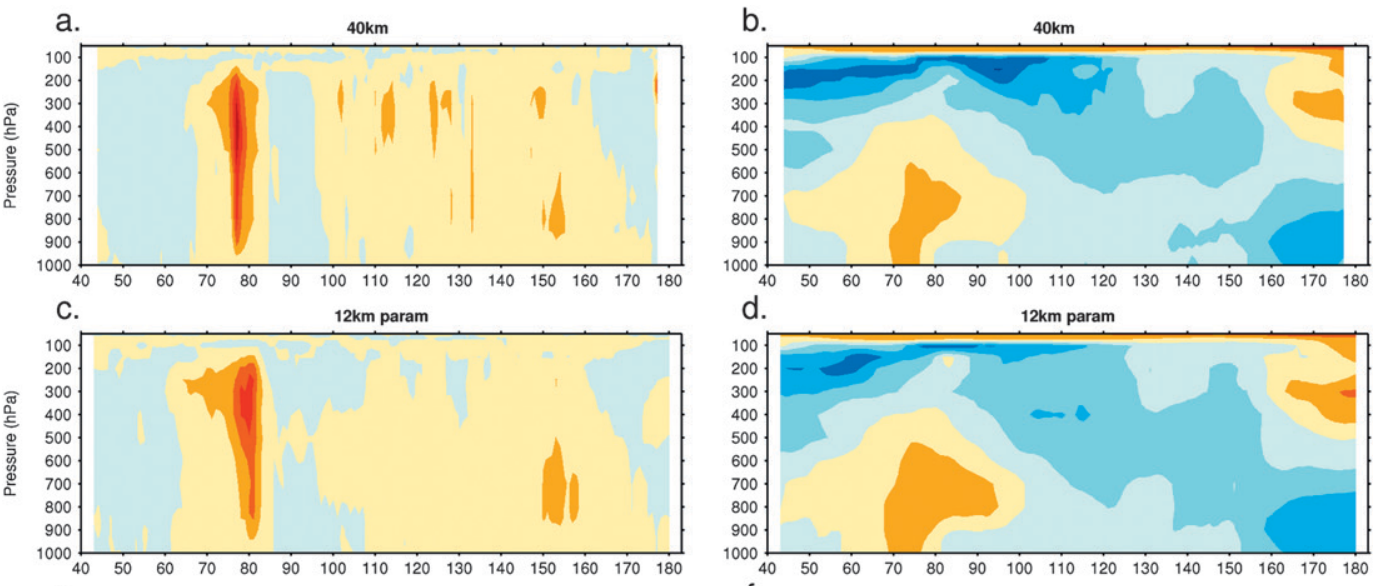

d. $12 \mathrm{~km}$ param
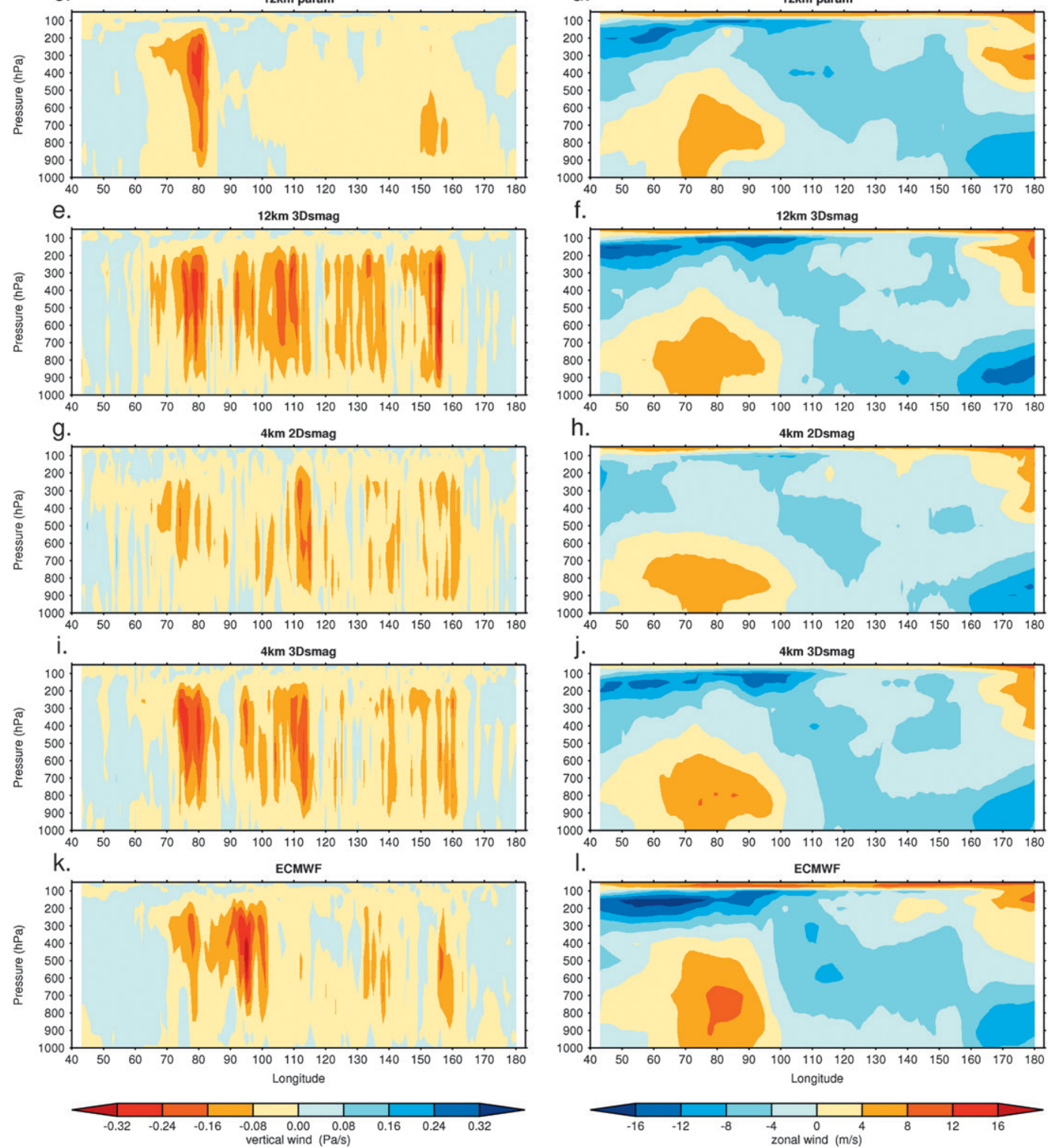

FIG. 7. Pressure velocity $\left(\mathrm{Pa} \mathrm{s}^{-1}\right)$ and zonal wind $\left(\mathrm{m} \mathrm{s}^{-1}\right)$ for five Cascade runs and ECMWF operational analyses daily average of four times for $10 \mathrm{Apr} 2009$ (0000, 0600, 1200, and $1800 \mathrm{UTC})$, averaged between $7.5^{\circ} \mathrm{S}$ and $7.5^{\circ} \mathrm{N}$ and onto a $1^{\circ}$ longitude grid.

model at the correct region around $140^{\circ} \mathrm{E}$ near the end of the period). The parameterized convection models also have a less realistic zonal wind pattern than the explicit convection models, with upper-level easterlies in the western part of the domain being too weak and too high, and lower-level westerlies not reaching down to the surface at their eastern limits. The latter weak or missing low-level westerlies must be associated with 

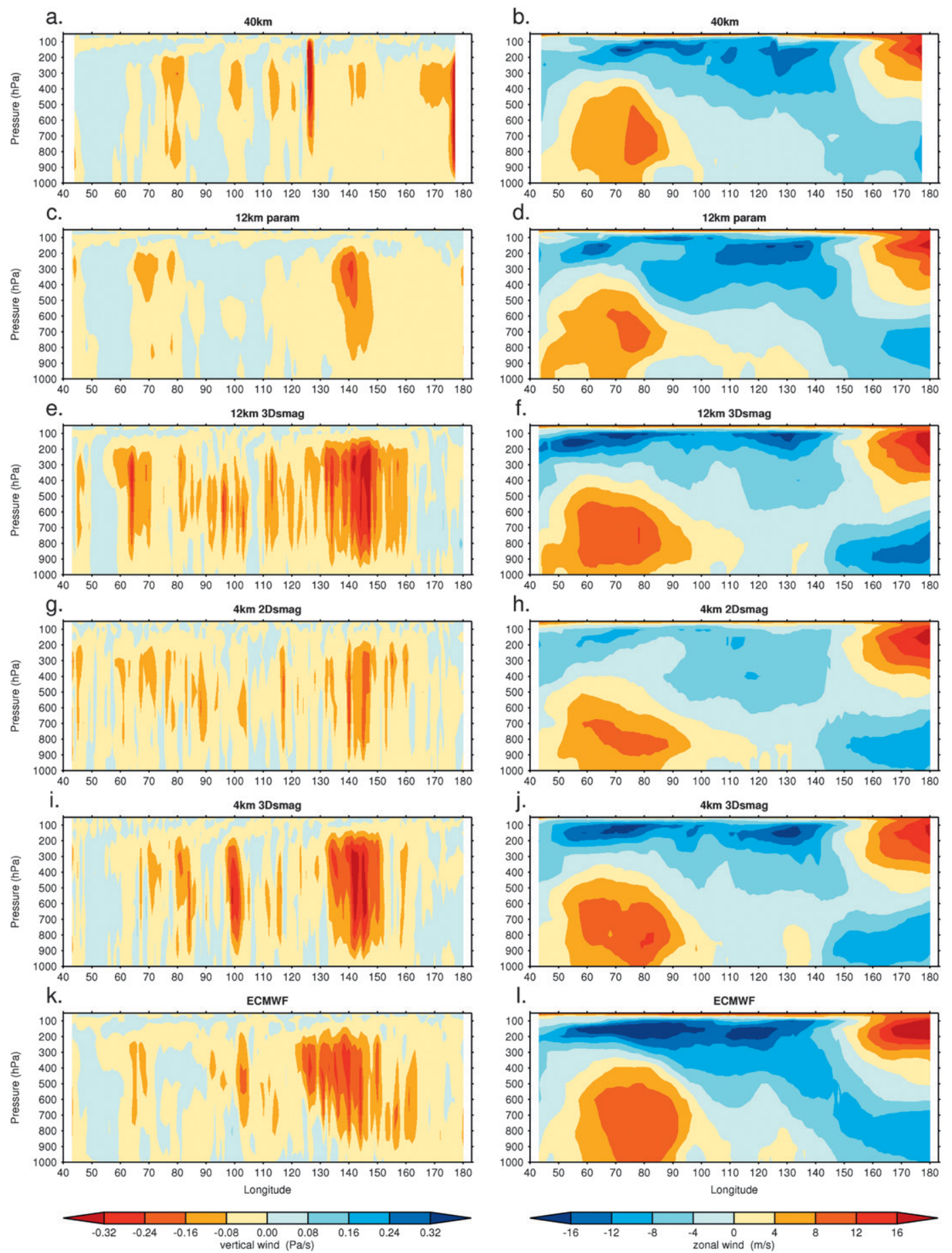

FIG. 8. Pressure velocity $\left(\mathrm{Pa} \mathrm{s}^{-1}\right)$ and zonal wind $\left(\mathrm{m} \mathrm{s}^{-1}\right)$ for five Cascade runs and ECMWF operational analyses daily average of four times for $15 \mathrm{Apr} 2009$ (0000, 0600,1200, and $1800 \mathrm{UTC})$, averaged between $7.5^{\circ} \mathrm{S}$ and $7.5^{\circ} \mathrm{N}$ and onto a $1^{\circ}$ longitude grid.

incorrect low-level convergence that is too far westward, agreeing with the fact that the ascent and rainfall do not move eastward from the central Indian Ocean in these models.
We show the equivalent vertical velocity and zonal wind figures for the other 7 days in the supplemental material (Figs. S2-S8) as a more complete reference for interested readers. 


\section{Humidity-precipitation relationship}

One process that appears to be better represented in the models with a more realistic MJO simulation (especially the 4-km 3Dsmag run) is the relationship between free-tropospheric humidity and rainfall. In Holloway et al. (2012), their Fig. 3, it was shown that the 4-km 3Dsmag model is more saturated in the free troposphere for light to moderate rainfall rates (below $0.4 \mathrm{~mm} \mathrm{~h}^{-1}$ ) than the $12-\mathrm{km}$ param model, and that the 4-km 3Dsmag model is more similar to ECMWF operational analysis humidity conditioned on TRMM rainfall for this case study. In that figure, in which saturation deficit was composited on rain rate for $1^{\circ} 3$-hourly averages, there was also a smaller change in lower-freetropospheric saturation deficit with rain rate for the models with a more realistic MJO and for ECMWF, suggesting a higher sensitivity between moisture and rainfall and potentially a stronger positive moistureconvection feedback. Precipitation and tropospheric moisture are strongly related to each other in observations, and theoretical work has posited that tropospheric moisture may play a fundamental role in the transition from weak to strong convection (Raymond 2000; Peters and Neelin 2006; Neelin et al. 2009; Muller et al. 2009). Moisture-convection feedback is strongly suspected to be important for the MJO (e.g., Grabowski and Moncrieff 2004; Maloney 2009). The relationship between humidity and precipitation can be strongly sensitive to entrainment rates in simple plume models and convective parameterizations (e.g., Derbyshire et al. 2004; Holloway and Neelin 2009), and larger values of entrainment, or evaporation of condensate, can lead to improved MJO variability in GCMs (Lin et al. 2006; Maloney 2009). Here, we look at the relationship between free-tropospheric humidity and rainfall in the different models and in ECMWF/TRMM. We expect that the free troposphere moistens to the east of the main convective region and dries at the main convective region and to the west; then, precipitation responds by moving from the drier, less favorable, currently active region to the moister, more favorable location to the east.

Figure 9 shows the saturation deficit anomaly for two equatorial regions over the 10 days. The mean, which is removed in the anomaly calculation, is taken over $7.5^{\circ} \mathrm{S}-$ $7.5^{\circ} \mathrm{N}$ and over all longitudes and times for each level and model or analysis. These mean saturation deficit profiles are shown in Fig. 2 and are discussed more in section $4 \mathrm{a}$, but here we concentrate on anomalies since differences in the means do not show a consistent relationship with MJO performance. Figure 9 shows that the 4-km 3Dsmag model has a stronger relationship between free-tropospheric moisture and rainfall for two regions around the equator during the case study, with dry air associated with suppressed convection over the Indian Ocean and moist air building up from the boundary layer to higher levels over the Maritime Continent in association with a transition to stronger precipitation there, more similar to ECMWF/TRMM. This relationship is explored in more detail in Holloway et al. (2012) — for instance, in the discussion of their Fig. 3.

At $70^{\circ}-80^{\circ} \mathrm{E}, \mathrm{ECMWF} / \mathrm{TRMM}$ shows drying in the lower-free troposphere from days 2.0 to 3.0 and further drying after day 4.5 ; this drying is associated with a fairly steep reduction in rainfall over those two periods. This is also seen in the 4-km 3Dsmag model, although the drying is most pronounced after day 3 and the rainfall never goes as low as TRMM. In the $12-\mathrm{km}$ param model and the 40-km model, however, the drying at low levels is associated with only a small reduction in rainfall, followed by remoistening after day 5.5 and a return to the same rainfall levels as in the first few days by day 7 . The main problem for these parameterized convection models appears to be that the rainfall does not respond enough to the drying in the first few days. The $12-\mathrm{km}$ 3Dsmag model is broadly similar to the 4-km 3Dsmag model, while the 4-km 2Dsmag model dries too quickly in this location and also loses convection too quickly.

At $130^{\circ}-140^{\circ} \mathrm{E}$, the most noticeable feature is the strong diurnal cycle in saturation deficit and precipitation. This is not the focus of the following discussion, however, since we are interested in the longer-term evolution of the MJO. The ECMWF/TRMM shows a slow lower-free-tropospheric moistening trend over the first 5 days followed by an eventual large increase in rainfall toward the end of the period, with some positive feedback suggested in that rainfall follows moistening but then sharp increases of rainfall are followed within hours by increased moisture. The other models mostly follow the conclusions from $70^{\circ}$ to $80^{\circ} \mathrm{E}$, with fairly similar behavior for the $4-\mathrm{km} 3$ Dsmag and $12-\mathrm{km}$ 3Dsmag models while the $12-\mathrm{km}$ param model gets the moistening correct but has no precipitation response. The 40-km model is even worse, actually drying near the end of the period. The 4-km 2Dsmag lacks the convective variability of the other explicit convection models and is also drier (in a relative sense).

In summary, the large-scale low-midlevel drying trend is there in most models for $70^{\circ}-80^{\circ} \mathrm{E}$, and the moistening trend in $130^{\circ}-140^{\circ} \mathrm{E}$, but only in the $4-\mathrm{km} 3$ Dsmag and $12-\mathrm{km} 3$ Dsmag is there a corresponding decrease of rainfall in the first case and increase in the second case as in ECMWF/TRMM, suggesting that the response of convection to changes in free-tropospheric moisture is not correct for the parameterized convection models. 

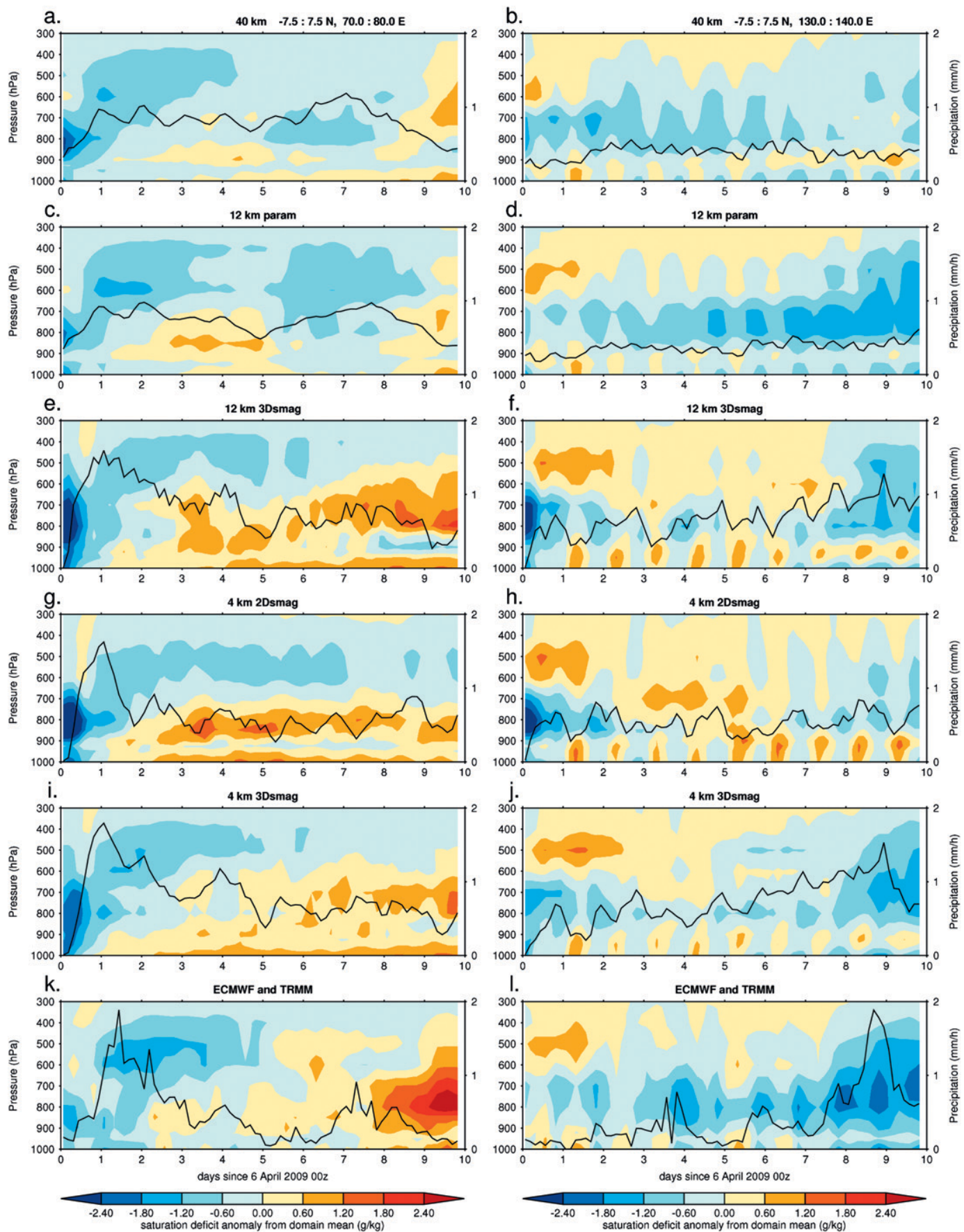

FIG. 9. Saturation deficit anomalies from the mean (contours, $\mathrm{g} \mathrm{kg}^{-1}$, where the mean is taken for each model/ analysis, over entire equatorial region and period, at each level, as shown in Fig. 2) and mean precipitation (black lines) in the boxes (left) $7.5^{\circ} \mathrm{S}-7.5^{\circ} \mathrm{N}, 70^{\circ}-80^{\circ} \mathrm{E}$ and (right) $7.5^{\circ} \mathrm{S}-7.5^{\circ} \mathrm{N}, 130^{\circ}-140^{\circ} \mathrm{E}$, for ECMWF operational analyses and TRMM precipitation and five Cascade runs for the 10-day case study.

This lack of correct moisture-convection feedback is one likely reason for the poor representation of the MJO in these models.

We show the equivalent saturation deficit anomaly figures for the other $10^{\circ}$ equatorial boxes in the supplemental material (Figs. S9-S14) as a more complete reference for interested readers. Although the relationship between free-tropospheric moisture and precipitation is not as clear in some of these boxes, particularly in parts of the Maritime Continent, we believe that the general 
conclusions reached above still hold for the MJO as a whole.

\section{Available potential energy generation and conversion on large scales}

To investigate the energetics of the MJO for this case, we have analyzed two terms from the global Lorenz energy cycle (Lorenz 1955): the generation of eddy available potential energy (APE) and the conversion from eddy available potential energy to eddy kinetic energy (KE). Although these are calculated using anomalies from zonal means within our limited domain, rather than anomalies at all longitudes taken from global zonal means, and therefore do not represent the same eddy energy terms calculated in other studies of this energy cycle, they should still give us an idea of whether APE is being generated by the large-scale heating and circulation and being converted into KE. It is hypothesized that these processes are necessary to grow and maintain an MJO.

To focus on the MJO, the domain considered in this section is limited in latitude as well as longitude to be approximately $7.5^{\circ} \mathrm{S}-7.5^{\circ} \mathrm{N}, 45^{\circ} \mathrm{E}-180^{\circ}$. To test the validity of our analysis on this limited domain, we have checked that the mean vertical velocity is small relative to the anomalies on this domain-that is, that both branches of the overturning circulation(s) are more or less included. Note, however, that this is still an area of net upward motion $\omega$ owing to the Hadley circulation and Pacific Walker circulation. The zonal and temporal average $\omega$ at $400 \mathrm{hPa}$ is $\{-0.047,-0.037,-0.036,-0.076$, $-0.058\} \mathrm{Pa} \mathrm{s}^{-1}$ for ECMWF, $40 \mathrm{~km}, 12-\mathrm{km}$ param, 12-km 3Dsmag, and 4-km 3Dsmag, respectively, with variations of zonal mean values over the period of around $\pm 50 \%$. The respective standard deviations at $400 \mathrm{hPa}$ for $\omega$ at all longitudes and times in the domain are $\{0.079,0.058,0.054,0.086,0.076\} \mathrm{Pa} \mathrm{s}^{-1}$, and the ratios of standard deviation to the absolute value of the mean are $\{1.7,1.6,1.5,1.1,1.3\} \mathrm{Pa} \mathrm{s}^{-1}$. The mean value magnitudes are several times smaller than the largest upward anomalies but of similar order of magnitude to the downward anomalies in the western part of the domain. However, it should be noted that the corresponding mean $\omega$ values over the entire domain of approximately $20^{\circ} \mathrm{S}-20^{\circ} \mathrm{N}, 42^{\circ} \mathrm{E}-180^{\circ}$ are $\{-0.019,-0.012$, $-0.019,-0.036,-0.025\} \mathrm{Pa} \mathrm{s}^{-1}$, which are roughly half of the means for the equatorial analysis domain, suggesting that much of the near-equatorial upward motion is associated with the Hadley circulation in our domain, as expected, and not part of any Walker circulations, which would be more problematic in terms of influencing zonal anomalies artificially owing to corresponding vertical motions outside of our domain. These results imply that while there is a significant mean component of the large-scale circulation captured in our analysis domain, it is somewhat smaller than the MJO signal within this domain, especially after taking the Hadley circulation into account, so there is some value in comparing the different models and ECMWF on this limited domain.

We have chosen to look at the two parameterized convection models (40-km and $12-\mathrm{km}$ param) and the 3D-Smagorinsky versions of the explicit convection models (4-km 3Dsmag and 12-km 3Dsmag). The 12-km 2Dsmag model was very similar to the $12-\mathrm{km} 3 \mathrm{Dsmag}$ model, and so it was excluded for clarity. The 4-km 2Dsmag model loses most of its large-scale zonally anomalous diabatic heating and upward motion after the first 3 days, as discussed above, and so the energetics terms are very small.

The equations for the eddy generation of APE and the eddy conversion from APE to KE in pressure coordinates are taken from Lorenz (1955). We ignore contributions from boundaries and adjustment factors for points on pressure surfaces that occur below the earth's surface. Again, given the limitations of the study, the terms calculated below should not be interpreted as terms in a balanced energy cycle, but they are useful for an overall energetics comparison.

The eddy generation term $G_{e}$ in pressure coordinates at a single time (again, on a limited domain) is

$$
G_{e}=\int \gamma\left[T^{*} Q^{*}\right] d m,
$$

where $T$ is temperature taken from instantaneous hourly output (but averaged every $3 \mathrm{~h}$ ). Also, and $Q=Q_{1}+Q_{R}$ is diabatic heating averaged for a 3-hourly period and consists of total radiational heating $Q_{R}$ plus a "subgrid" term $Q_{1}$ defined as in Eq. (5) of Holloway et al. (2012):

$$
Q_{1}=L(c-e)-\frac{\Pi}{\bar{\rho}} \frac{\partial \overline{\rho w^{\prime} \theta^{\prime}}}{\partial z},
$$

where $L$ is the latent heat of condensation, $c$ is condensation, $e$ is evaporation of condensate (only liquidvapor phase transitions are included in the equations for simplicity, although in the model calculations ice phase transitions are also accounted for), $\theta$ is potential temperature, $w$ is the vertical velocity, $\rho$ is the density, $z$ is height, $\Pi$ is the Exner function defined as

$$
\Pi=\left(\frac{\bar{p}}{p_{0}}\right)^{R / c_{p}},
$$

$R$ is the gas constant for dry air, $c_{p}$ is the specific heat capacity for dry air at constant pressure, $p$ is the pressure, 
and $p_{0}=1000 \mathrm{hPa}$ is the reference pressure. The term $X^{\prime}$ is the anomaly of quantity $X$ from $\bar{X}$, which is the horizontal average of $X$ at a single level and time over the "large scale" ( $1^{\circ}$ in latitude and longitude in this case). Note that $Q_{1}$ is calculated on 3 -hourly, $1^{\circ}$ latitudelongitude boxes on model (hybrid height) levels, using the original model grid spacing (e.g., $4 \mathrm{~km}$ ) to calculate $X^{\prime}$, before being coarse grained to $5^{\circ}$ longitude, $7.5^{\circ} \mathrm{S}-$ $7.5^{\circ} \mathrm{N}$ averages on pressure levels for the $G_{e}$ calculation. The term $X^{*}$ is the zonal anomaly of quantity $X$, which has been previously coarse grained to $5^{\circ}$ longitude, $7.5^{\circ} \mathrm{S}-7.5^{\circ} \mathrm{N}$ averages on pressure levels; $[X]$ is the zonal mean of $X$ on the limited domain; $d m$ is the mass element; and $\gamma$ is the inverse mean static stability factor defined as

$$
\gamma=\frac{-\theta R}{T p c_{p}}\left(\frac{\partial \tilde{\theta}}{\partial p}\right)^{-1}
$$

where $\tilde{\theta}$ is the domain and time mean of $\theta$ at each pressure level [from Eqs. (9) and (24) of Lorenz (1955)]. Therefore, $\gamma$ depends only on pressure and is outside of the brackets in Eq. (1), although we do multiply by $\gamma$ even when we show terms in $G_{e}$ that have not been zonally averaged. The radiative heating $Q_{R}$, although included in $Q$, contributes very little to $Q^{*}$ since it is fairly zonally homogenous.

Similarly, we can calculate the conversion from eddy APE to eddy KE at a single time, $C_{e}$, as

$$
C_{e}=-\int\left[\alpha^{*} \omega^{*}\right] d m
$$

where $\alpha$ is the specific volume (using $\alpha=R T / p$ ) and $\alpha$ is the pressure velocity. Note that $T$ and $\omega$ have been taken from hourly instantaneous values every $6 \mathrm{~h}$ in order to compare directly with ECMWF values, which are available at that temporal resolution (we do not use ECMWF for $G_{e}$ comparisons because the diabatic heating increments are likely to depend on the model convection scheme). We use dry density, but this should be fairly accurate since the important density anomaly contributions are in the upper troposphere where specific humidity is very small (this weighting toward the upper troposphere comes from the $p^{-1}$ dependence of $\alpha^{*}$ as compared with $T^{*}$ and is analogous to the effectively upper-troposphere-heavy $\gamma$ weighting for $G_{e}$, which is discussed more below).

Steinheimer et al. (2008) find that subgrid values of $C_{e}$, which in our case would mean at scales below $5^{\circ}$, both resolved and parameterized, can contribute significantly to global $C_{e}$, being about $50 \%$ of the grid scale $C_{e}$. While this is an interesting result that is worth future investigation, it is beyond the scope of the present study, which is attempting to compare the larger-scale energetics between models and reanalyses with very different subgrid processes.

In the following plots, we express energetics terms as specific energy $\left(\mathrm{W} \mathrm{kg}^{-1}\right)$ except for vertical integrals ( $\mathrm{W} \mathrm{m}^{-2}$ ).

Time-mean profiles of the zonally averaged (but not vertically integrated) values of the APE generation and conversion covariance terms, as well as the correlations between their two factors in each case, are shown in Figs. 10a,b,e,f. Figures 10c,d,g,h show the time mean of the (zonal) standard deviation of each component (such as $Q$ and $\omega$ ). Figure 11 shows the values of $\gamma$ at each pressure level for the four models. The gamma values are very similar among all models at most levels, with a fairly constant value at all levels from 925 to $500 \mathrm{hPa}$, then increasing rapidly with height to a peak value about 4-5 times larger than this at 250-200 hPa (except about 6 times larger for the 12-km 3Dsmag model) before decreasing back to much lower values at and above the $100-\mathrm{hPa}$ level. The main differences are at the lowest levels, with the explicit convection models having values about half of those for the parameterized convection models because of less near-surface stability in the latter. The magnitudes of the generation and conversion terms in Figs. 10a,e are similar, but the vertically integrated generation terms are slightly larger than the vertically integrated conversion terms (see vertical integral discussion below).

There are notable negative correlations in the middle levels of the troposphere for the $40-\mathrm{km}$ and $12-\mathrm{km}$ param models in Figs. 10b,f, suggesting that convective heating is taking place preferentially in locations with anomalously low temperatures at those levels (perhaps because of the CAPE closure in the parameterizations), and that upward motions are also occurring at these locations (the opposite would be true for locations with anomalously high temperatures). However, the effect of these negative correlations on $G_{e}$ and $C_{e}$ is small at most levels, mainly because of the $p^{-1}$ dependence of $\gamma$ and $\alpha$ that results in weighting toward the upper-tropospheric levels. In fact, because $\gamma$ is about 3-4 times larger in the upper troposphere $(\sim 250-200 \mathrm{hPa})$ than it is in the rest of the free troposphere $(800-400 \mathrm{hPa})$, the relative contributions to $G_{e}$ are much larger in the upper troposphere than they would be if we had just used $T^{*} Q^{*}$ as in some other studies, such as Zhou et al. (2012); although the correlations are still important, they may not tell the whole story of MJO energetics both because of the upper-tropospheric weighting and the effect of amplitude of $T^{*}$ and $Q^{*}$ on covariances. A similar argument 
a.

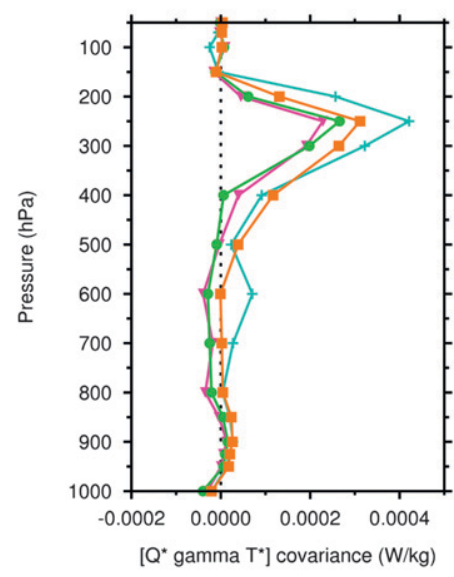

e.

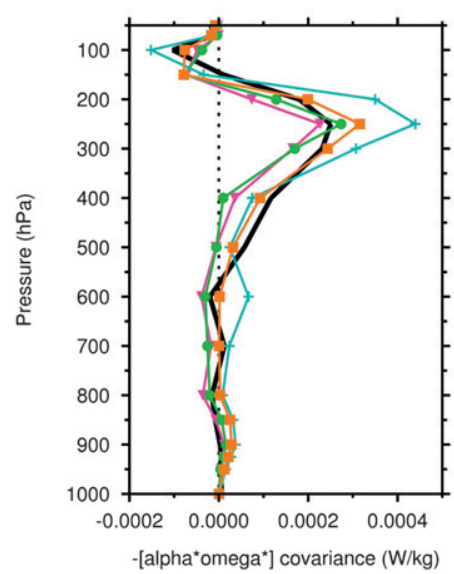

b.

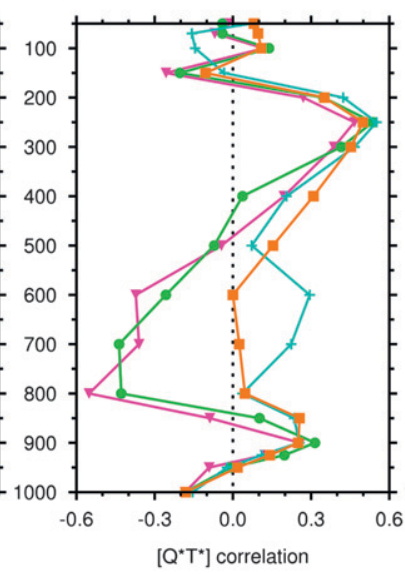

f.

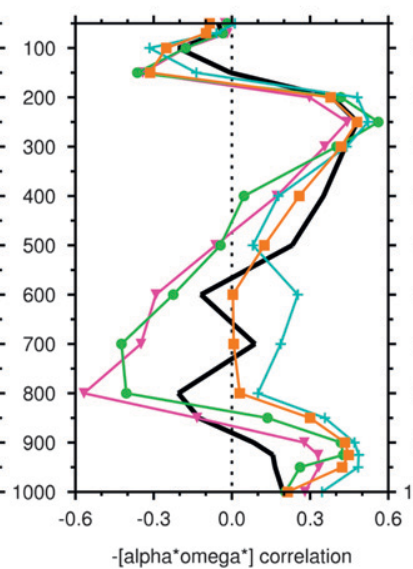

C.

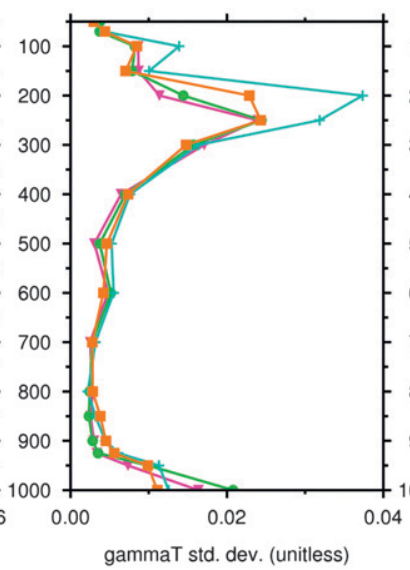

g.

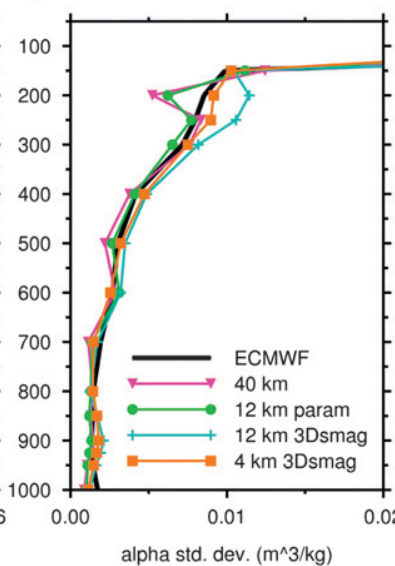

d.

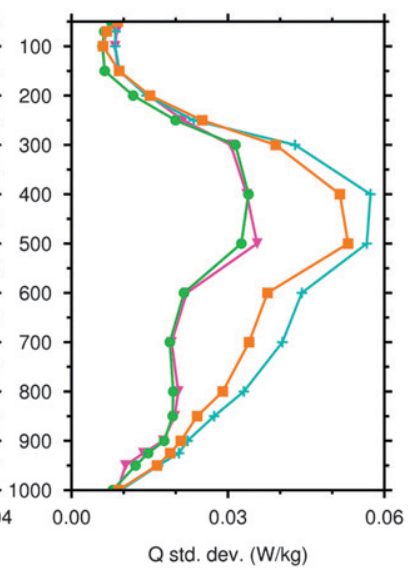

h.

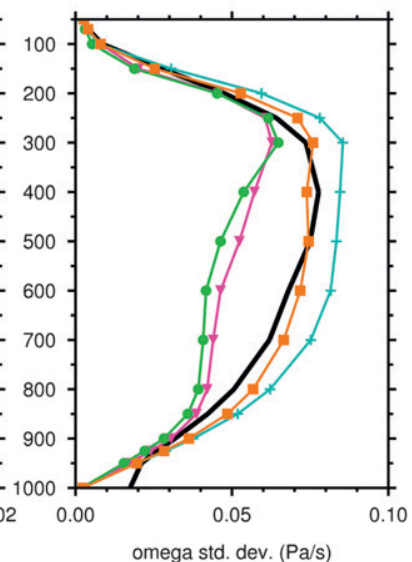

FIG. 10. Time-mean profiles of (a) covariance and (b) correlation of [ $\left.Q^{*} \gamma T^{*}\right]$, zonal standard deviation of (c) $\gamma T$ and (d) $Q$, (e) covariance and (f) correlation of $-\left[\alpha^{*} \omega^{*}\right]$, and standard deviation of $(\mathrm{g}) \alpha$ and $(\mathrm{h}) \omega$, for the 10-day case study, for four Cascade runs [(e)-(h) also shows ECMWF], averaged between $7.5^{\circ} \mathrm{S}$ and $7.5^{\circ} \mathrm{N}$ and originally onto a $5^{\circ}$ longitude grid.

applies if $T^{*} \omega^{*}$ is used instead of $\alpha^{*} \omega^{*}$. Shutts (2008) used the full $G_{e}$ formulation, as in the present study and found an upper-tropospheric peak of $G_{e}$ (evaluated at wavenumber 10 on an equatorial beta-plane simulation of an anisotropic CSRM) at around 10-km height.

However, there is some impact of negative correlations at certain times (not shown) in the parameterized convection models around 500-400 hPa (which contribute to time-mean correlations at these pressure levels in Figs. 10b,f that are near zero). At these levels, the $40-\mathrm{km}$ and $12-\mathrm{km}$ param models have significantly lower correlations and covariances than the other models. There are also small but significant negative covariances in the parameterized convection models between 800 and $500 \mathrm{hPa}$ that contribute to the overall smaller $G_{e}$ and $C_{e}$ vertically integrated values for these models.

Note that the lower correlations in the $40-\mathrm{km}$ and $12-\mathrm{km}$ param models at midtropospheric levels (as compared with higher correlations in the upper troposphere around $250 \mathrm{hPa}$ ) are due to opposite-signed temperature anomalies between the middle and upper troposphere in these models, since the anomalies of diabatic heating and vertical velocity are fairly coherent in the vertical. In other words, at longitudes with significant anomalous diabatic heating (or vertical velocity) in these models, the temperature anomaly changes sign between the upper and middle troposphere. Further work is needed to determine whether these temperature anomalies are caused by the convection itself, for instance because of top-heavy heating causing excessive adiabatic cooling at midlevels, or if there is some other explanation, such as a possible tendency for the parameterization closure to trigger in regions with cold midlevel anomalies.

The standard deviation profiles (Figs. 10c,d,g,h) show that, just in terms of scale analysis and ignoring the effects of correlation, the amplitude of the covariance 


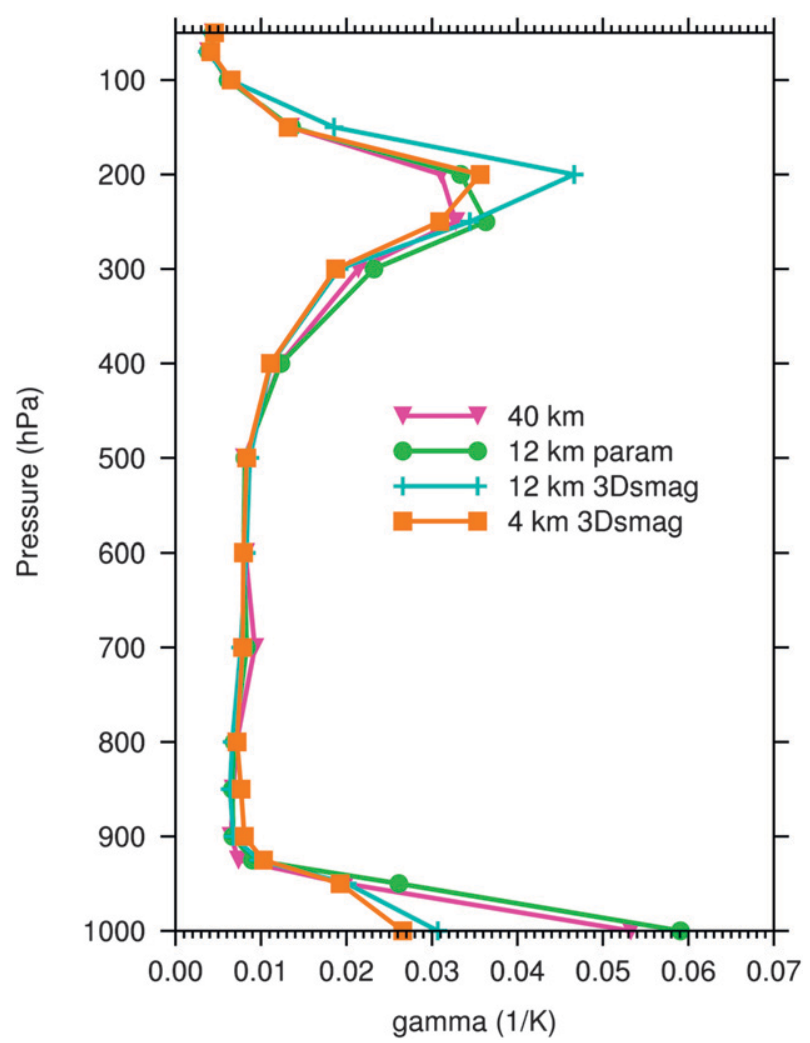

FIG. 11. Inverse mean static stability $\gamma\left(\mathrm{K}^{-1}\right)$ for domain and time mean for the 10-day case study, for four Cascade runs averaged between $7.5^{\circ} \mathrm{S}$ and $7.5^{\circ} \mathrm{N}$.

profiles depend on the intersection of the differently sloped curves of each of their component factors. From 500 to $400 \mathrm{hPa}$, the larger contributions for the explicit convection models are attributable mainly to the fact that there are significant positive correlations between diabatic heating and temperature (and between upward motion and temperature) for these models, whereas the correlations for the parameterized convection models are close to zero, as discussed above. However, the amplitudes of the anomalies, as measured by the standard deviations, are also larger for the explicit convection models, which means that higher correlations alone for the parameterized convection models would not eliminate these differences. At $300 \mathrm{hPa}$, correlations are more similar, though still somewhat larger for the explicit convection models, while the higher-amplitude anomalies of diabatic heating and vertical motion for these models also play a role in their larger $G_{e}$ and $C_{e}$ values. At $250 \mathrm{hPa}$, the models are largely in agreement, although the $12-\mathrm{km}$ 3Dsmag model is significantly higher than all of the other models at this and nearby levels because of especially large-amplitude temperature anomalies. At $200 \mathrm{hPa}$, there are also significantly smaller-amplitude temperature anomalies for the parameterized convection models compared with both explicit convection models and ECMWF, which is the main contributor to lower $G_{e}$ and $C_{e}$ contributions at that level.

We can make an attempt to separate the contributions to differences in the total vertically integrated time mean $G_{e}$ and $C_{e}$ terms into three main categories: 1) differences in correlation, 2) differences in standard deviation of $Q$ or $\omega$, and 3) differences in standard deviation of $\gamma T$ or $\alpha$. By grouping the differences at different vertical levels into these categories, we can estimate rough percentages of contribution to the difference between the 4-km 3Dsmag and 12-km param models (as representative models). As an approximation, the differences in covariance from 800 to $500 \mathrm{hPa}$ are determined mainly by category 1 and the differences in covariance from $250-300 \mathrm{hPa}$ are determined mainly by category 2. The differences in covariance at 850 and $400 \mathrm{hPa}$ are related to differences in both categories 1 and 2, so we assume that each category contributes half of the covariance differences at these two levels. Finally, the differences in covariance at $200 \mathrm{hPa}$ are determined mainly by category 3 , while the remaining levels have negligible covariance differences. By vertically integrating the covariance differences for the layers assigned to each category (with some half-contributions as indicated above) and dividing by the total vertically integrated difference, we can estimate the percentage contributions to the covariance differences in these two models from four categories $(1,2,3$, and residual differences), respectively, as follows: $\{49 \%, 38 \%, 11 \%$, $3 \%\}$ for $C_{e}$ and $\{50 \%, 36 \%, 10 \%, 4 \%\}$ for $G_{e}$. Thus, by this crude metric, roughly half of the contribution to the larger terms in the 4-km 3Dsmag model, compared to the $12-\mathrm{km}$ param model, result from stronger correlations between component factors in the middle troposphere, while the remaining half comes mainly from larger standard deviations of those component factors at levels with significant positive correlations. It is interesting to note that the profiles of the different components in ECMWF in Figs. 10e-h resemble those of the explicit convection models more than those of the parameterized convection models-for instance, in the lower extent of the positive correlations and significant covariances and in the standard deviation of $\omega$.

Figure 12 shows the vertical integrals of the zonally averaged $G_{e}$ and $C_{e}$ terms as daily means. The parameterized convection models have smaller values for both terms, which is associated with both a narrower uppertropospheric layer of high anomaly correlations as well as slightly smaller $[Q]$ and $[\omega]$ standard deviations (Fig. 10). The 4-km 3Dsmag model looks most like ECMWF in 
gamma $\left[\mathrm{Q}^{\star} \mathrm{T}^{\star}\right]$ vert. integ. (1000-150 hPa)

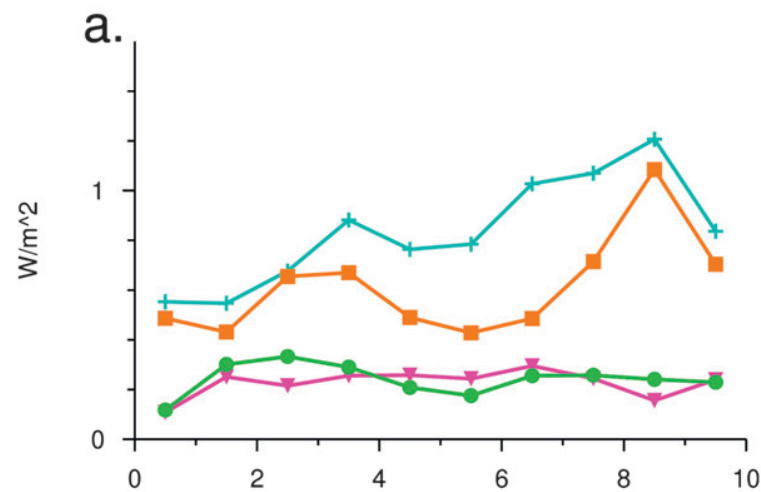

- [alpha*omega*] vert. integ. (1000-150 hPa)

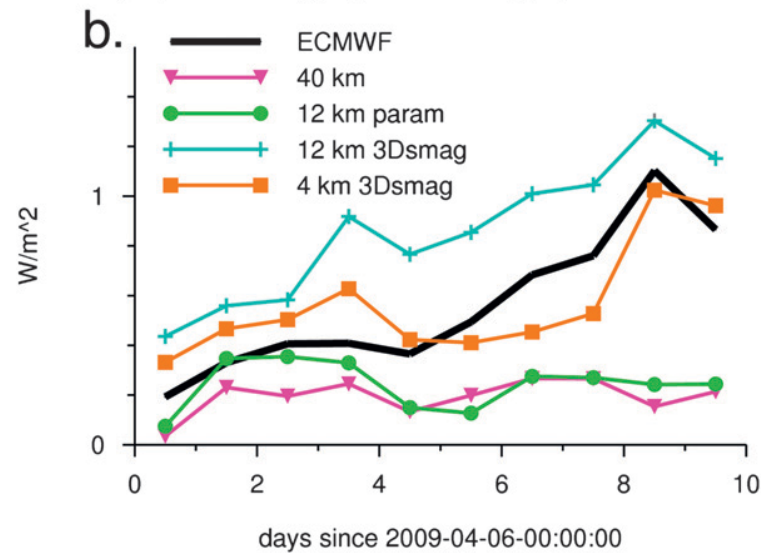

FIG. 12. Daily mean vertically integrated (a) $G_{e}$ and (b) $C_{e}$ (both in $\mathrm{W} \mathrm{m}^{-2}$ ) for the 10-day case study, for four Cascade runs [(b) also shows ECMWF], averaged between $7.5^{\circ} \mathrm{S}$ and $7.5^{\circ} \mathrm{N}$ and originally onto a $5^{\circ}$ longitude grid.

the $C_{e}$ terms. The MJO intensifies during the period in ECMWF and the explicit convection models, at least in terms of $C_{e}$ (and $G_{e}$ for the models). This agrees with the stronger signal by 15 April in vertical velocity and zonal winds for these models and ECMWF (Fig. 8). If we assume that the KE being converted from APE is mostly being dissipated, it makes sense that there are stronger winds (more KE) later in the period for these models and ECMWF. This also agrees with the larger standard deviation of $\omega$ for the explicit convection models and ECMWF in Fig. 10.

For the 4-km 3Dsmag model at least, $G_{e}$ leads $C_{e}$ at certain key times, including the third and eighth days (before the two peaks). In fact, $G_{e}$ tends to lead $C_{e}$ by about $12 \mathrm{~h}$ when plotted at higher temporal resolution (not shown), suggesting that, as expected, APE is first being generated by the diabatic heating and then this APE is being converted to KE shortly after.
To investigate the spatial structure of the energetics terms and their component factors, in Figs. 13-16 we next show 2-day averages of the anomaly product terms for $G_{e}$ and $C_{e}$ (i.e., $\gamma T^{*} Q^{*}$ and $-\alpha^{*} \omega^{*}$ ) along with the anomaly factors; the factors, such as $Q^{*}$ and $T^{*}$, have been averaged in time over the 2-day periods in the figures, so their product is not exactly the same as the 2-day averages of the product terms that they are being compared to, but there are not big differences. The strength of the contributions to $G_{e}$ and $C_{e}$ from different longitudes is not independent from each other, since the zonal anomalies that contribute to the anomaly product terms are taken from zonal means, which in turn reflect activity at all longitudes. For example, stronger upward motion in the east for a given model will result in larger calculated downward anomalies in subsidence regions to the west for that model, all else being equal. Furthermore, the location of the largest-amplitude values of the anomaly product terms does not matter for the full $G_{e}$ and $C_{e}$ terms shown in Fig. 12. However, we believe that these figures do give insight into important differences in the way that processes in the models affect both the strength and propagation of the MJO.

Figure 13 shows that over days 2.0-4.0, the explicit convection models are starting to have significant anomalous diabatic heating (black contour lines) around $95^{\circ}-$ $105^{\circ} \mathrm{E}$, while the $12-\mathrm{km}$ param model and $40-\mathrm{km}$ model have only very weak anomalous heating there and are developing subsidence over $85^{\circ}-95^{\circ} \mathrm{E}$. This corresponds to larger upper-tropospheric $\gamma T^{*} Q^{*}$ in the parameterized convection models over $75^{\circ}-85^{\circ} \mathrm{E}$. The $12-\mathrm{km}$ param model has significantly larger upper-tropospheric $\gamma T^{*} Q^{*}$ around $75^{\circ}-85^{\circ} \mathrm{E}$ compared with the other models, mainly because there is a much larger $\gamma T^{*}$.

Figure 14 shows that the $12-\mathrm{km}$ param model at this time has large $C_{e}$ contribution terms around $75^{\circ}-85^{\circ} \mathrm{E}$, similar to ECMWF (but about $5^{\circ}$ farther west and of significantly larger amplitude); this is again due to positive $\alpha^{*}$ at these longitudes in the $12-\mathrm{km}$ param model. The $40-\mathrm{km}$ model has $C_{e}$ contribution terms and $\alpha^{*}$ closer to ECMWF, although they are also not far enough to the east, since there has not been significant eastward propagation of convection since the beginning of the run. The explicit convection models already have significant $C_{e}$ contribution terms far to the east-perhaps too early-and they have higher magnitudes of these terms around $45^{\circ}-55^{\circ} \mathrm{E}$ (where all models have at least some positive $C_{e}$ contribution terms from negative heating anomalies located in a suppressed region with anomalously cool temperatures). The anomalies to the east are due to both larger anomalous upward motion and larger $\alpha^{*}$, while the western anomalies are higher mainly because of higher $\alpha^{*}$. While the $12-\mathrm{km}$ param 

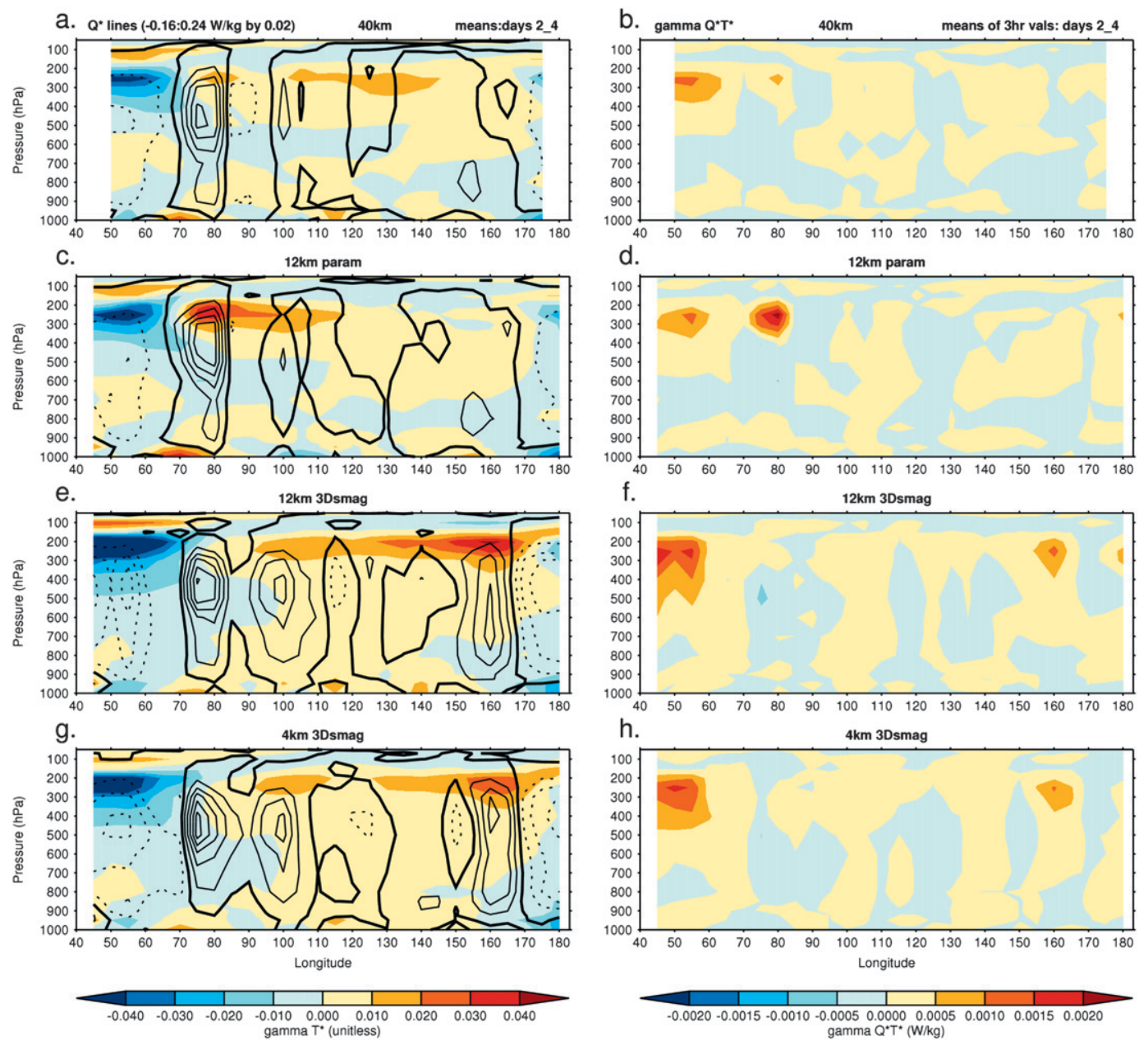

FIG. 13. (right) Zonal anomalies of diabatic heating (black contours, zero line is thicker and contour interval is $0.02 \mathrm{~W} \mathrm{~kg}^{-1}$; dashed lines negative) and temperature scaled by inverse static stability (color contours, unitless), and (right) the product of these, averaged over days 2.0-4.0 of the case study, for four Cascade runs, averaged between $7.5^{\circ} \mathrm{S}$ and $7.5^{\circ} \mathrm{N}$ and onto a $5^{\circ}$ longitude grid.

model looks very similar to ECMWF during days 2.0-4.0 in the full $C_{e}$ term in Fig. 12 and in the anomaly product terms in the right-hand column of Fig. 14, it is already apparent that the $12-\mathrm{km}$ param model lacks the $Q^{*}$ and $-\omega^{*}$ around $95^{\circ}-105^{\circ} \mathrm{E}$ that seems important for the ongoing development and propagation of the MJO (the explicit convection models and ECMWF develop anomalous upward motion in this region in days 4.0-6.0 associated with the eastward propagation of the MJO, as shown in the supplemental material (Fig. S18), whereas the parameterized convection models do not, perhaps suggesting that this lack of anomalous heating is the first place and time where these models "go wrong").

Figures $15-16$ show that by days $8-10$, the generation and conversion anomaly product terms in the parameterized convection models are much weaker than in the explicit convection models (and in ECMWF in the case of the conversion term). Furthermore, the $12-\mathrm{km}$ param model still has significant generation and conversion contributions over $75^{\circ}-85^{\circ} \mathrm{E}$, corresponding with too much anomalous upward motion and diabatic heating there along with anomalous positive temperature anomalies that are not present in the other models or ECMWF at these longitudes. The $40-\mathrm{km}$ model lacks any significant generation or conversion contributions east of the Indian Ocean. The stronger signal in the explicit convection models and in ECMWF in Fig. 16 is due to both stronger pressure velocity anomalies and a larger gradient in specific volume. Although the explicit convection models do not agree with ECMWF on the exact position of these anomalies, the strength is similar among all three.

The equivalent figures for Figs. 13-16 for the remaining three 2-day periods are shown in the supplemental 

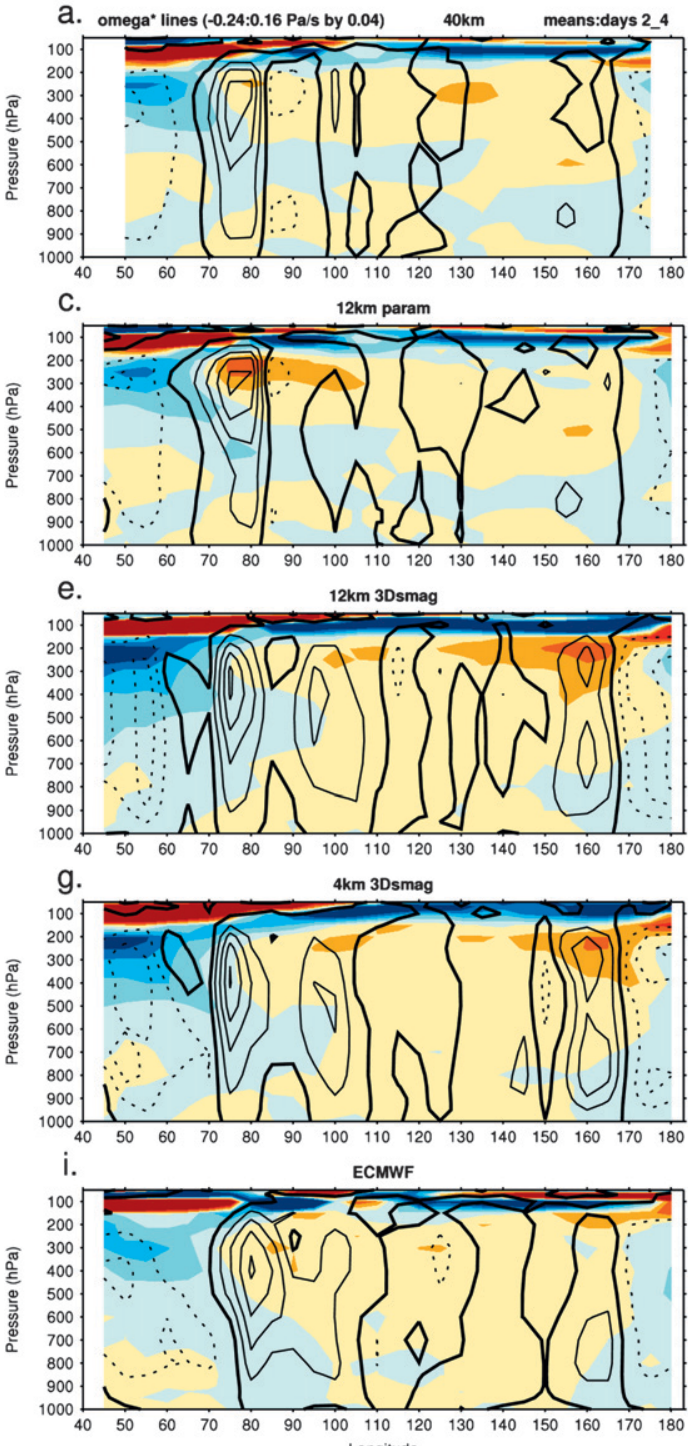

Longitude

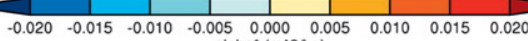

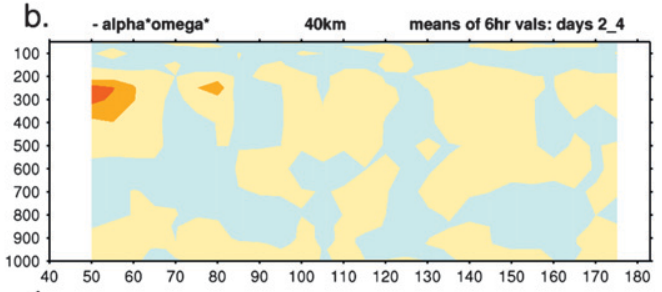

d. $\quad 12 \mathrm{~km}$ param

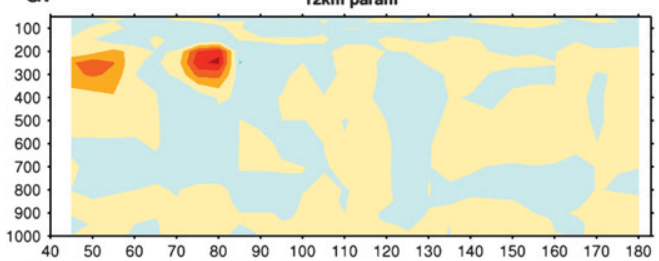

f.

$12 \mathrm{~km}$ 3Dsmag
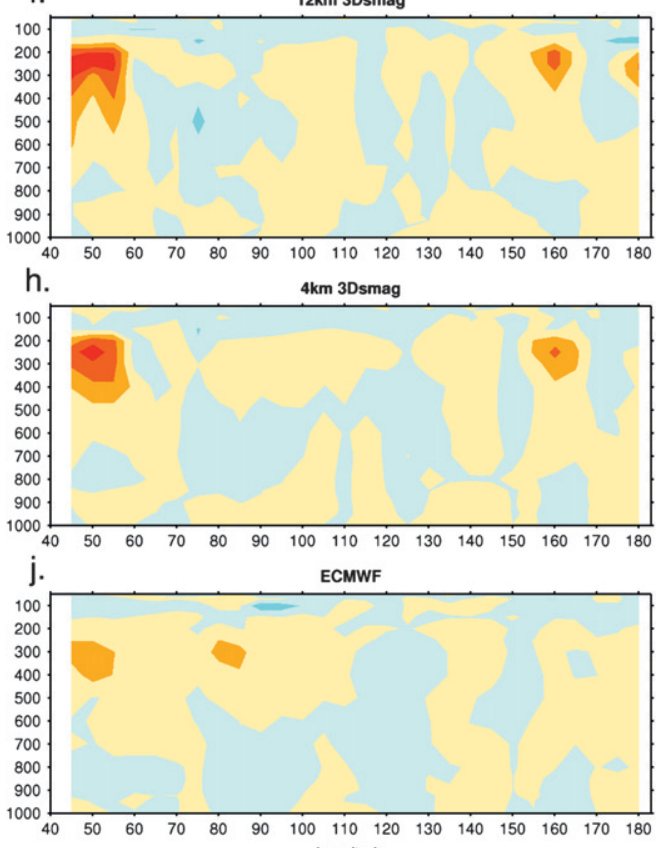

Longitude

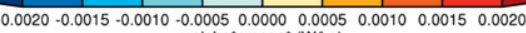

FIG. 14. (left) Zonal anomalies of pressure velocity (black contours, zero line is thicker and contour interval is $0.04 \mathrm{~Pa} \mathrm{~s}^{-1}$; dashed lines positive for downward motion) and specific volume (color contours, $\mathrm{m}^{3} \mathrm{~kg}^{-1}$ ), and (right) the product of these, averaged over days 2.0-4.0 of the case study, for four Cascade runs, averaged between $7.5^{\circ} \mathrm{S}$ and $7.5^{\circ} \mathrm{N}$ and onto a $5^{\circ}$ longitude grid.

material (Figs. S15-S20). One interesting feature is that heating in the explicit convection runs during days $0-2$ between $95^{\circ}$ and $105^{\circ} \mathrm{E}$ is followed by upward motion there in the next several days as the MJO moves east, while in the parameterized convection runs this region experiences increasing subsidence.

One hypothesis we are testing is that convective parameterizations destroy temperature anomalies because they are slaved to CAPE, causing convective heating in exactly the locations with negative tropospheric temperature anomalies. In general, this does not seem to be the case in these analyses, with positive correlations between heating and temperature anomalies (relating to $G_{e}$ ) for all models at the energetically most important levels between about 400 and $200 \mathrm{hPa}$. However, the mean correlations are significantly weaker, and sometimes negative (particularly at individual times, which are not shown), for the parameterized convection between about 500 and $350 \mathrm{hPa}$, where there are still significant mean positive correlations and covariances in 

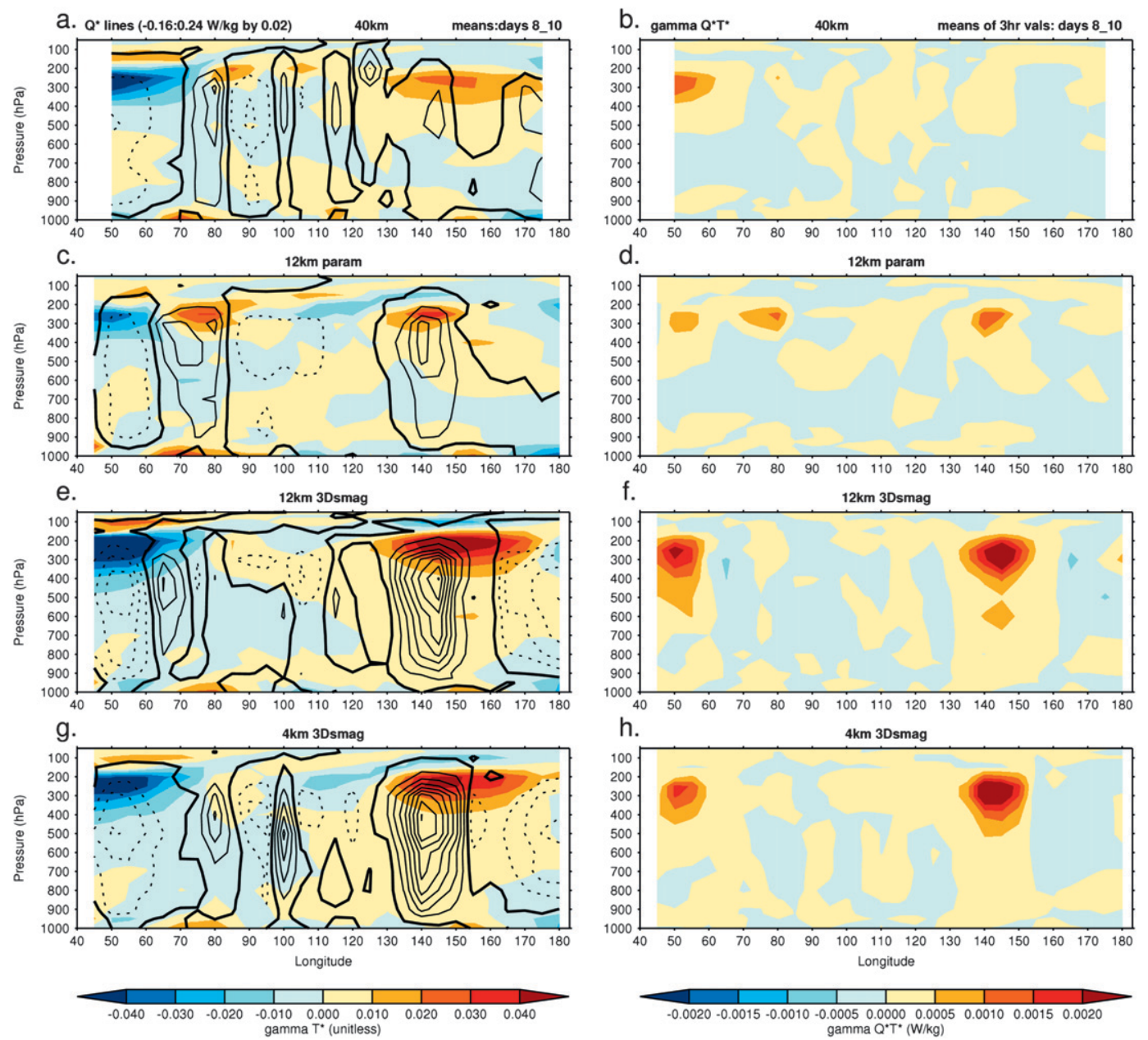

FIG. 15. As in Fig. 13, but for days 8.0-10.0.

the explicit convection models. There are also small negative covariances from 800 to $500 \mathrm{hPa}$ that contribute to the smaller vertically integrated $G_{e}$. For the corresponding correlations and covariances relating to $C_{e}$, significant mean positive values are found at these levels in both the explicit convection models and ECMWF, while they are again missing in the $40-\mathrm{km}$ and $12-\mathrm{km}$ param models. Therefore, as discussed above with respect to Fig. 10, it may be possible that the smaller vertical extent of significant positive correlations between convective heating anomalies and temperature anomalies is important in explaining the weaker MJO and more stationary convective regions in the parameterized convection models.

\section{Summary and discussion}

To test the importance of the interaction between convective scales and larger scales for the ability to simulate the MJO, we have run and analyzed six limitedarea simulations of the Met Office Unified Model at different horizontal grid spacing and using both explicit and parameterized convection for a 10-day case in April 2009 over the Indo-Pacific warm-pool region. Our main finding is that the explicit versus parameterized convection makes the largest difference in the simulations, rather than the horizontal resolution per se, and that the explicit convection models produce a more realistic MJO as measured against TRMM rainfall measurements, ECMWF operational analyses, and NCEPNCAR reanalysis principal components similar to those calculated in Wheeler and Hendon (2004).

One caveat, and cautionary tale, is that explicit convection alone is not enough to simulate the $\mathrm{MJO}$ in this case. Although it showed eastward propagation of convection in the first few days of simulation, the $4-\mathrm{km}$ 2Dsmag model, which was closest to the operational 4-km U.K. forecast model at the time we ran our 

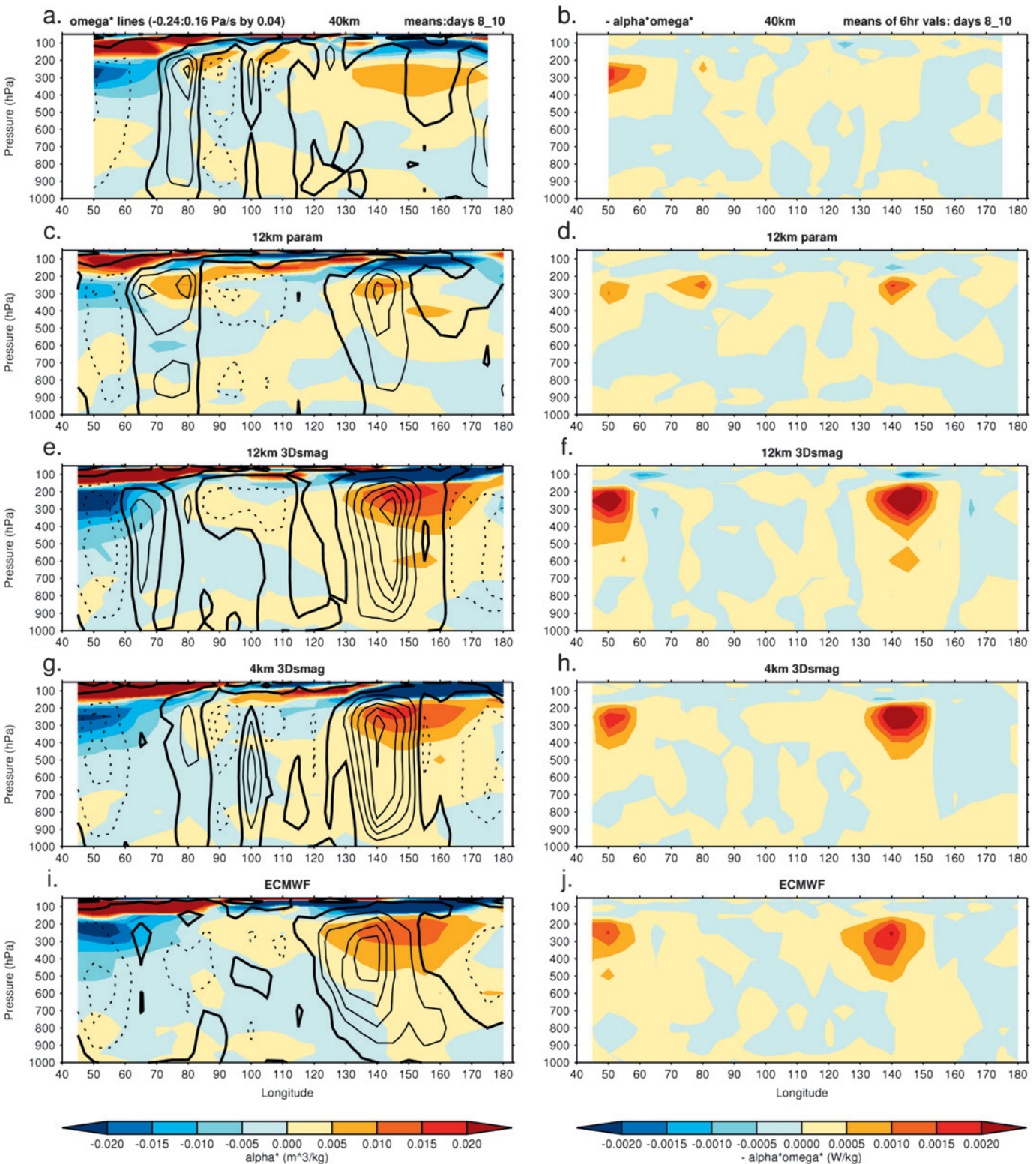

FIG. 16. As in Fig. 14, but for days 8.0-10.0.

simulation, lost the large-scale organization of the MJO within a few days after the beginning of the run. This loss of organization is associated with too little mixing above the subcloud layer, which in turn is partly due to settings in the boundary layer scheme that caused the nonlocal scheme to mix only between the surface and just below the LCL whenever a convective boundary layers is diagnosed. This makes sense if the convection scheme is operating normally above the LCL, but in the explicit convection models it is not allowed to do this. This shows the importance of developing the remaining parameterizations in a CSRM, such as microphysics, radiation, and, in this case, subgrid mixing, to be consistent with explicit convection.

We recognize that 4-km (and especially $12 \mathrm{~km}$ ) grid spacing is too coarse to adequately resolve deep convection explicitly. Furthermore, other studies have shown that global models using parameterized convection, in which the convective parameterization has been modified to increase the entrainment mixing and/or the fraction of rainfall that evaporates into subsaturated air to form downdrafts, can produce realistic hindcasts of MJO events as well as greatly improved climatologies of tropical intraseasonal variability (e.g., Tokioka et al. 
1988; Maloney 2009; Kim et al. 2011). In fact, recent research using a global version of the UM similar to our $40-\mathrm{km}$ model, but with 1.5 times more lateral entrainment and detrainment, greatly improved both of these measures of MJO simulation performance (N. P. Klingaman and S. J. Woolnough 2012, unpublished manuscript). In the present study, explicit convection may be providing enhanced interaction between convection and environmental humidity, perhaps through larger effective entrainment and mixing or through increased evaporation of rainfall and subsaturated downdrafts. This does not mean that the convective parameterization could not be modified in such a way as to capture many of the benefits that we have seen from using explicit convection. At the same time, there are likely certain features that parameterized convection at 12 or $40 \mathrm{~km}$ simulates better than explicit convection at 4 or $12 \mathrm{~km}$ and vice versa. These are issues that would benefit from future investigation.

We have explored two possible reasons why three of the explicit convection models have a more realistic MJO than the parameterized convection models. One reason is that the relationship between precipitation and free-tropospheric water vapor is more realistic in these three models, with deep convection following lowmidlevel moistening and suppressed convective conditions following low-midlevel drying. This also relates to findings in Holloway et al. (2012) that even areas with relatively light rain have a moister lower free troposphere in the explicit convection models that have a better MJO than they do in the parameterized convection models. In the present study, the parameterized convection models seem to simulate the correct change in the large-scale moistening to the east of the active convective region and drying at the active region and to the west, but they fail to simulate the response of the convection to this environmental development, leading to insufficient eastward propagation of the MJO.

The second reason that might explain why three of the explicit convection models have a more realistic MJO than the parameterized convection models is that the explicit convection models have larger values for the generation of APE and the conversion from APE to KE, as seen in Fig. 12. These larger terms are due to both a deeper layer of significant positive correlations between diabatic heating and temperature (and between upward motion and temperature) in the middle-upper troposphere and to larger-amplitude anomalies of diabatic heating (and upward motion) where these positive correlations are present (Fig. 10). At the 200-hPa level, there are also significantly-smaller-amplitude temperature anomalies for the parameterized convection models, which is the main contributor to lower $G_{e}$ and
$C_{e}$ contributions at that level for the $40-\mathrm{km}$ and $12-\mathrm{km}$ param models. The 12-km 3Dsmag model has larger values of $G_{e}$ and $C_{e}$ than even the 4-km 3Dsmag model from 250 to $200 \mathrm{hPa}$ mainly because it has even-largeramplitude temperature anomalies at these levels.

Another finding of this study is that very different MJO simulations can result from limited-area models forced (ultimately) from the same boundary conditions. This refutes one potential criticism of the limited-area, one-way nesting approach-namely, that the boundary conditions determine the large-scale behavior of the simulation including the MJO phase and amplitude. We have shown that a model's treatment of small-scale processes, such as convection and boundary layer mixing, can have a large effect on the fidelity of the largescale circulation including the MJO. Indeed, there are very large differences between all of these simulations and the operational analyses away from the lateral boundaries, and some of the deficiencies in the parameterized convection models resemble deficiencies generally seen for MJO events in global free-running simulations at similar resolutions. This suggests that limited-area modeling can be an instructive tool for studying these deficiencies even if it is not a completely "fair" test of model skill as compared with observations.

In fact, all models in this study have significant deficiencies in forecasting some aspects of the large-scale circulation despite the updated operational analysis boundary conditions "giving them the answer" at the lateral boundaries. We cannot tell, however, whether the models with relatively realistic large-scale simulations would have lost this fidelity (or even perhaps improved) if they were run instead in a global model framework with no updated information in the future. It is very possible that part of the skill seen in some of these simulations comes from these operational analyses at the lateral boundaries. Global model runs of explicit convection models compared to limited-area runs over the same case would be useful to test the robustness of the limited-area framework, although they are beyond the scope of this project and of the current UM framework. Another, more tractable, problem would be to perform these comparisons for coarser, parameterized convection simulations, preferably using a model with an improved MJO.

The other, contradictory potential criticism of the limited-area, one-way nesting approach is that, because the lateral boundary conditions do not include the response of external atmospheric phenomena to the free-running model interior (although there are some potential feedbacks, discussed below and in Holloway et al. 2012), it is actually more difficult to simulate the MJO than using a global version of the same model. This 
argument is somewhat analogous to the argument that you cannot accurately simulate the MJO without an interactive ocean model, and is largely refuted by the fairly realistic MJO in the explicit convection models in the present study, particularly the 4-km 3Dsmag model.

Another simplification in our simulations is that the SSTs are prescribed and fixed at their initial observed values. While the MJO does interact with the upper ocean in nature, this interaction does not appear to be fundamental to the simulation of the MJO, with atmosphere-ocean coupling mainly resulting in some slowing and intensification of the wave compared with uncoupled simulations in a study using the ECMWF model (Woolnough et al. 2007). However, it is possible that CSRMs have a different response to air-sea coupling (Grabowski 2006) and this could also depend on whether a simulation is run as a short hindcast, as in this study, or for longer periods, as in MMF simulations discussed in Benedict and Randall (2011). We also found little difference in coarse-resolution sensitivity tests using prescribed SSTs updated daily instead of fixed from the initial time.

The findings in this paper point to several potentially fruitful research directions to improve the understanding and simulation of organized tropical convection. First, we echo other researchers in stressing the need for improved understanding of moisture-convection interactions, including entrainment processes. Second, given that other studies have also pointed to the apparent importance of energetics terms in simulating organized tropical convection (e.g., Shutts 2008; Zhou et al. 2012), this study indicates the need for more research in the MJO community to evaluate physical processes contributing to differences in these terms. This includes the investigation of negative correlations between temperature anomalies and diabatic heating (and between temperature anomalies and vertical velocity) in the middle troposphere. There may also be a relationship between the ability of a model to generate and maintain an MJO and its ability to generate sufficient variance in large-scale vertical velocity and diabatic heating; this in turn relates to the ability of a model to generate a realistic distribution of precipitation (cf. Holloway et al. 2012). This suggests a further need to understand why certain models struggle to produce adequate variability in these fields. Finally, we have shown that large-scale tropical convective organization can be sensitive to the particular configuration of vertical subgrid mixing, at least at one horizontal resolution of a particular model version.

Part II of this research will present more analysis of how the MJO develops in the different models and of what physical processes play a role in producing a better
MJO in most of the explicit convection models. This will include more analysis of humidity-precipitation relationships and vertical heating profiles and how these change with MJO phase. This will provide insight into ways that the convective parameterization could be improved to produce an MJO as good as the explicit convection model, as well as the mechanisms that may be important for MJO development and propagation in nature.

Acknowledgments. We have used ECMWF operational analyses from the YOTC online archive. Interpolated OLR data and NCEP-NCAR reanalysis data provided by the NOAA/OAR/ESRL PSD, Boulder, Colorado, United States, from their website at http:// www.esrl.noaa.gov/psd/. We thank Adrian Matthews for useful discussions and for providing rainfall data in NetCDF format. Thanks to Steve Derbyshire, Mike Blackburn, and Julia Slingo for useful discussions. This work made use of the facilities of HECToR, the United Kingdom's national high-performance computing service, which is provided by UoE HPCx Ltd at the University of Edinburgh, Cray Inc, and NAG Ltd, and funded by the Office of Science and Technology through EPSRC's High End Computing Programme. This research was carried out with funding from NERC Grant NE/E00525X/1.

\section{REFERENCES}

Benedict, J. J., and D. A. Randall, 2009: Structure of the MaddenJulian oscillation in the superparameterized CAM. J. Atmos. Sci., 66, 3277-3296.

— Madden-Julian oscillation structure in the superparameterized CAM. J. Atmos. Sci., 68, 1990-2008.

Bretherton, C. S., M. E. Peters, and L. E. Back, 2004: Relationships between water vapor path and precipitation over the tropical oceans. J. Climate, 17, 1517-1528.

Davies, T., M. J. P. Cullen, A. J. Malcolm, M. H. Mawson, A. Staniforth, A. A. White, and N. Wood, 2005: A new dynamical core for the Met Office's global and regional modelling of the atmosphere. Quart. J. Roy. Meteor. Soc., 131, 1759-1782.

Derbyshire, S. H., I. Beau, P. Bechtold, J.-Y. Grandpeix, J.-M. Piriou, J.-L. Redelsperger, and P. M. M. Soares, 2004: Sensitivity of moist convection to environmental humidity. Quart. J. Roy. Meteor. Soc., 130, 3055-3080.

Fuchs, Z., and D. J. Raymond, 2002: Large-scale modes of a nonrotating atmosphere with water vapor and cloud-radiation feedbacks. J. Atmos. Sci., 59, 1669-1679.

Grabowski, W. W., 2003: MJO-like coherent structures: Sensitivity simulations using the cloud-resolving convection parameterization (CRCP). J. Atmos. Sci., 60, 847-864.

, 2006: Impact of explicit atmosphere-ocean coupling on MJO-like coherent structures in idealized aquaplanet simulations. J. Atmos. Sci., 63, 2289-2306. 
— convection parameterization for modeling the tropical convecting atmosphere. Physica $D, \mathbf{1 3 3}, 171-178$.

— , and M. W. Moncrieff, 2004: Moisture-convection feedback in the tropics. Quart. J. Roy. Meteor. Soc., 130, 3081-3104.

Gregory, D., and P. R. Rowntree, 1990: A mass flux convection scheme with representation of cloud ensemble characteristics and stability-dependent closure. Mon. Wea. Rev., 118, 14831506.

Hannah, W. M., and E. D. Maloney, 2011: The role of moistureconvection feedbacks in simulating the Madden-Julian oscillation. J. Climate, 24, 2754-2770.

Holloway, C. E., and J. D. Neelin, 2009: Moisture vertical structure, column water vapor, and tropical deep convection. J. Atmos. Sci., 66, 1665-1683.

— , S. J. Woolnough, and G. M. S. Lister, 2012: Precipitation distributions for explicit versus parametrized convection in a large-domain high-resolution tropical case study. Quart. J. Roy. Meteor. Soc., 138, 1692-1708.

Huffman, G. J., and Coauthors, 2007: The TRMM Multisatellite Precipitation Analysis (TMPA): Quasi-global, multiyear, combined-sensor precipitation estimates at fine scales. $J$. Hydrometeor., 8, 38-55.

Janowiak, J. E., R. J. Joyce, and Y. Yarosh, 2001: A real-time global half-hourly pixel-resolution infrared dataset and its applications. Bull. Amer. Meteor. Soc., 82, 205-217.

Kalnay, E., and Coauthors, 1996: The NCEP/NCAR 40-Year Reanalysis Project. Bull. Amer. Meteor. Soc., 77, 437-471.

Khairoutdinov, M. F., and D. A. Randall, 2001: A cloud resolving model as a cloud parameterization in the NCAR community climate system model: Preliminary results. Geophys. Res. Lett., 28, 3617-3620.

Kiladis, G. N., K. H. Straub, and P. T. Haertel, 2005: Zonal and vertical structure of the Madden-Julian oscillation. J. Atmos. Sci., 62, 2790-2809.

Kim, D., A. H. Sobel, E. D. Maloney, D. M. W. Frierson, and I.-S. Kang, 2011: A systematic relationship between intraseasonal variability and mean state bias in AGCM simulations. J. Climate, 24, 5506-5520.

Lean, H. W., P. A. Clark, M. Dixon, N. M. Roberts, A. Fitch, R. Forbes, and C. Halliwell, 2008: Characteristics of highresolution versions of the Met Office Unified Model for forecasting convection over the United Kingdom. Mon. Wea. Rev., 136, 3408-3424.

Liebmann, B., and C. A. Smith, 1996: Description of a complete (interpolated) outgoing longwave radiation dataset. Bull. Amer. Meteor. Soc., 77, 1275-1277.

Lin, J.-L., and Coauthors, 2006: Tropical intraseasonal variability in 14 IPCC AR4 climate models. Part I: Convective signals. J. Climate, 19, 2665-2690.

Liu, C., and M. W. Moncrieff, 2004: Effects of convectively generated gravity waves and rotation on the organization of convection. J. Atmos. Sci., 61, 2218-2227.

Liu, P., and Coauthors, 2009: An MJO simulated by the NICAM at 14- and 7-km resolutions. Mon. Wea. Rev., 137, 3254-3268.

Lock, A. P., A. R. Brown, M. R. Bush, G. M. Martin, and R. N. B. Smith, 2000: A new boundary layer mixing scheme. Part I: Scheme description and single-column model tests. Mon. Wea. Rev., 128, 3187-3199.

Lorenz, E. N., 1955: Available potential energy and the maintenance of the general circulation. Tellus, 7, 157-167.

Love, B. S., A. J. Matthews, and G. M. S. Lister, 2011: The diurnal cycle of precipitation over the Maritime Continent in a high-resolution atmospheric model. Quart. J. Roy. Meteor. Soc., 137, 934-947.

Madden, R. A., and P. R. Julian, 1994: Observations of the 40-50-day tropical oscillation-A review. Mon. Wea. Rev., 122, 814837.

Majda, A. J., and J. A. Biello, 2004: A multiscale model for tropical intraseasonal oscillations. Proc. Natl. Acad. Sci. USA, 101, 4736-4741.

__ and S. N. Stechmann, 2009: A simple dynamical model with features of convective momentum transport. J. Atmos. Sci., 66 , 373-392.

Maloney, E. D., 2009: The moist static energy budget of a composite tropical intraseasonal oscillation in a climate model. J. Climate, 22, 711-729.

_ , and D. L. Hartmann, 1998: Frictional moisture convergence in a composite life cycle of the Madden-Julian oscillation. J. Climate, 11, 2387-2403.

Miura, H., M. Satoh, T. Nasuno, A. T. Noda, and K. Oouchi, 2007: A Madden-Julian Oscillation event realistically simulated by a global cloud-resolving model. Science, 318, 1763-1765.

Miyakawa, T., Y. N. Takayabu, T. Nasuno, H. Miura, M. Satoh, and M. W. Moncrieff, 2012: Convective momentum transport by rainbands within a Madden-Julian oscillation in a global nonhydrostatic model with explicit deep convective processes. Part I: Methodology and general results. J. Atmos. Sci., 69, 1317-1338.

Muller, C. J., L. E. Back, P. A. O'Gorman, and K. A. Emanuel, 2009: A model for the relationship between tropical precipitation and column water vapor. Geophys. Res. Lett., 36, L16804, doi:10.1029/2009GL039667.

Nasuno, T., H. Miura, M. Satoh, A. T. Noda, and K. Oouchi, 2009: Multi-scale organization of convection in a global numerical simulation of the December 2006 MJO event using explicit moist processes. J. Meteor. Soc. Japan, 87, 335-345.

Neelin, J. D., and J.-Y. Yu, 1994: Modes of tropical variability under convective adjustment and the Madden-Julian oscillation. Part I: Analytical theory. J. Atmos. Sci., 51, 1876-1894.

— O. Peters, and K. Hales, 2009: The transition to strong convection. J. Atmos. Sci., 66, 2367-2384.

Ohring, G., A. Gruber, and R. Ellingson, 1984: Satellite determinations of the relationship between total longwave radiation flux and infrared window radiance. J. Climate Appl. Meteor., 23, 416-425.

Oouchi, K., A. T. Noda, M. Satoh, H. Miura, H. Tomita, T. Nasuno, and S. Iga, 2009: A simulated preconditioning of typhoon genesis controlled by a boreal summer Madden-Julian Oscillation event in a global cloud-system-resolving model. SOLA, 5, 65-68.

Pearson, K. J., R. J. Hogan, R. P. Allan, G. M. S. Lister, and C. E. Holloway, 2010: Evaluation of the model representation of the evolution of convective systems using satellite observations of outgoing longwave radiation. J. Geophys. Res., 115, D20206, doi:10.1029/2010JD014265.

Peters, O., and J. D. Neelin, 2006: Critical phenomena in atmospheric precipitation. Nat. Phys., 2, 393-396.

Raymond, D. J., 2000: Thermodynamic control of tropical rainfall. Quart. J. Roy. Meteor. Soc., 126, 889-898.

Roberts, N. M., 2003: Theq impact of a change to the use of the convection scheme to high-resolution simulations of convective events. UK Met Office Tech. Rep. 407, 30 pp.

Shutts, G., 2006: Upscale effects in simulations of tropical convection on an equatorial beta-plane. Dyn. Atmos. Oceans, 42 , $30-58$. 
, 2008: The forcing of large-scale waves in an explicit simulation of deep tropical convection. Dyn. Atmos. Oceans, 45, 125.

Sobel, A. H., and E. D. Maloney, 2012: An idealized semi-empirical framework for modeling the Madden-Julian oscillation. J. Atmos. Sci., 69, 1691-1705.

,,-- G. Bellon, and D. M. Frierson, 2008: The role of surface fluxes in tropical intraseasonal oscillations. Nat. Geosci., 1, 653-657.

,,-- , and,- 2010 : Surface fluxes and tropical intraseasonal variability: A reassessment. J. Adv. Model. Earth Syst., 2 (1), 27 pp., doi:10.3894/JAMES.2010.2.2.

Steinheimer, M., M. Hantel, and P. Bechtold, 2008: Convection in Lorenzs global energy cycle with the ECMWF model. Tellus, 60A, 1001-1022.

Taniguchi, H., W. Yanase, and M. Satoh, 2010: Ensemble simulation of Cyclone Nargis by a global cloud-system-resolving model-Modulation of cyclogenesis by the Madden-Julian Oscillation. J. Meteor. Soc. Japan, 88, 571-591.

Tian, B., D. E. Waliser, E. J. Fetzer, B. H. Lambrigtsen, Y. L. Yung, and B. Wang, 2006: Vertical moist thermodynamic structure and spatial-temporal evolution of the MJO in AIRS observations. J. Atmos. Sci., 63, 2462-2485.

Tokioka, T., K. Yamazaki, A. Kitoh, and T. Ose, 1988: The equatorial 30-60 day oscillation and the Arakawa-Schubert penetrative cumulus parameterization. J. Meteor. Soc. Japan, 66, 883-901.

Waliser, D. E., and Coauthors, 2008: Year of Tropical Convection (YOTC): The YOTC Science Plan: A joint WCRP-WWRP/ THORPEX International Initiative. World Meteorological Organization Tech. Rep. WMO/TD 1452, WCRP 130, WWRP/ THORPEX 9, 26 pp. [Available online at http://www.ucar. edu/yotc/documents/YOTC_Science_Plan.pdf.]

— , and Coauthors, 2012: The "Year" of Tropical Convection (May 2008-April 2010): Climate variability and weather highlights. Bull. Amer. Meteor. Soc., 93, 1189-1218.

Wheeler, M. C., and H. H. Hendon, 2004: An all-season real-time multivariate MJO index: Development of an index for monitoring and prediction. Mon. Wea. Rev., 132, 1917-1932.

Wilson, D. R., and S. P. Ballard, 1999: A microphysically based precipitation scheme for the UK Meteorological Office Unified Model. Quart. J. Roy. Meteor. Soc., 125, 1607-1636.

Woolnough, S. J., F. Vitart, and M. A. Balmaseda, 2007: The role of the ocean in the Madden-Julian Oscillation: Implications for MJO prediction. Quart. J. Roy. Meteor. Soc., 133, 117-128.

Zhou, L., R. B. Neale, M. Jochum, and R. Murtugudde, 2012: Improved Madden-Julian oscillations with improved physics: The impact of modified convection parameterizations. J. Climate, 25, 1116-1136. 